\title{
Should I default on my mortgage even if I can pay? Experimental evidence $e^{\text {th }}$
}

\author{
Marina Pavan a , Iván Barreda-Tarrazona ${ }^{\mathrm{a}, \mathrm{b}, *}$ \\ a LEE E' Economics Department, Universitat Jaume I, Castellón, Spain \\ ${ }^{\mathrm{b}}$ CERME E' Management and Economics Departments, Università Ca'Foscari, Venezia, Italy
}

\section{A R T I C L E I N F O}

\section{Article history:}

Received 14 October 2018

Revised 31 May 2019

Accepted 16 August 2019

Available online $\mathrm{xxx}$

\section{JEL classification:}

C91

E70

E21

G41

\section{Keywords:}

Strategic mortgage default

Negative equity

Household indebtedness

Housing

Laboratory experiment

\begin{abstract}
A B S T R A C T
We study strategic default in the laboratory, i.e., in a controlled experiment. Subjects are initially endowed with a house and a mortgage (we use neutral wording in the experiment), and must decide at each period in which their mortgage is alive among three options: making the mortgage payment, selling the house, or walking away from their house and defaulting on their mortgage. At each point in time, we can observe whether defaulters can afford to make the mortgage payment, and thus, directly compute the number of strategic defaulters. Subjects default in the right periods and quite fast learn what they should consume. We find experimental support for the "double trigger" hypothesis: individuals faced with low income and low house prices are more likely to default. We observe that subjects default less than optimal, and this decision is significantly affected by social norm concerns in the context of the experiment. Individuals under-consume in the first periods of life: they are "cautious" when indebted. Both introducing a 50\% probability of recourse and a Responsible Homeowner Reward are very effective in preventing default in the lab, especially by individuals receiving a bad shock to income when house prices are low.
\end{abstract}

(c) 2019 Elsevier B.V. All rights reserved.

\section{Introduction}

The 2007-2008 bust in house prices left millions of homeowners in the U.S. and in many other countries with negative house equity, that is, with an outstanding mortgage debt exceeding the market value of their house. Not surprisingly, mortgage default rates rose during the crisis. Due to the economically harsh times, many of the homeowners that defaulted on their mortgage simply could not afford to make the payments. Some others, though, are likely to have decided that it did not make any financial sense to continue payments, particularly if the institutional framework allowed them to start (almost) afresh. Borrowers who stop servicing their mortgage despite their ability to pay are called "strategic", and represent a potentially serious problem to the economy, given that they contribute to deepening

\footnotetext{
is The paper benefited from constructive comments by two anonymous referees, Michele Bernasconi, Charles Noussair and participants at the 9th Workshop on Theoretical and Experimental Macroeconomics, Berlin, July 2018, and BEAM-ABEE Workshop, Amsterdam, August 2018. Financial support by the Spanish Ministry of Science, Innovation and University (RTI2018-096927-B-100 and ECO2015-68469-R), Generalitat Valenciana (AICO/2018/036 and PROMETEO/2018/102) and Jaume I University (P1.1B2015-76/77) is gratefully acknowledged.

* Corresponding author.

E-mail addresses: pavan@eco.uji.es (M. Pavan), ivan.barreda@eco.uji.es (I. Barreda-Tarrazona).
} 
the decline in house prices and create a negative externality on their neighbors. ${ }^{1}$ In this paper, we use a laboratory experiment to perfectly identify strategic default behavior, and link it to economic conditions (income, house prices, assets, etc.), moral and social norm concerns and other individual characteristics, under three different institutional arrangements.

Identifying strategic default is very difficult: it requires detailed data on the borrowers' income and balance sheet, to determine their ability to pay. Some studies use loan-level data and define as strategic defaulters those individuals who did not make any mortgage payments for 180 days or more, while being current on all their other debts (credit cards, car loans, etc.). Using this measure, Experian-Oliver Wyman (2011) reports that in 2008 about $20 \%$ of total U.S. defaults were strategic. Guiso et al. (2013) collect questionnaire data and obtain an estimate of strategic default that ranges from $26 \%$ in 2009 to 35\% in 2010. Gerardi et al. (2018) use data from the Panel Study of Income Dynamics (PSID) surveys between 2009 and 2013 and identify strategic defaulters as those households in default that have the ability to meet their mortgage payments without having to reduce their level of consumption. According to this definition, $38 \%$ of defaults in their sample are strategic. $^{2}$ Recently, Artavanis and Spyridopoulos (2018) obtain a $28 \%$ strategic default rate in primary residence mortgages for Greece, exploiting a natural experiment. On the other hand, Gerardi et al. (2018) as well as Bhutta et al. (2017) and White (2010) underline that the majority of (U.S.) homeowners continued to make their mortgage payments despite being deeply underwater. That is, the repayment decision must depend on reasons other than the purely rational motive driven by equity concerns. The sense of guilt or shame of foreclosure, the fear of the perceived consequences of default, a wrong subjective evaluation of house equity, optimistic expectations on future house prices, or the special attachment to one's own home can play a very important role.

Unfortunately, information on social norms, individual moral concerns, perceived future risks or costs of default is missing in most datasets. ${ }^{3}$ Moreover, the observed data do not often allow for policy analysis: how would strategic default behavior change under a stricter recourse policy? Or under different mortgage conditions?

We intend to alleviate these difficulties by studying strategic default in the laboratory, that is, in an environment in which we control for default costs, agents' risk and mortgage conditions. First, we build a dynamic model of individual default decisions, and we parameterize it such that it generates many situations in which default is the utility maximizing choice. In the model, all default is strategic. Second, we compare the model predictions with observed behavior in the laboratory. In the economic experiment, based on our theory, we endow individuals with a house and a mortgage (in a neutral framework), and have them choose at each experimental period for the whole duration of the mortgage life among three options: making the mortgage payment, selling the house and prepaying the mortgage, or walking away from their house and defaulting. In the last two cases, they have to rent for the rest of the decision periods. Subjects face shocks to their employment status and to the market value of houses with a known probability, must decide how much to consume, and have the possibility of accumulating liquid wealth. House price shocks are such that house equity is negative in the first periods of the mortgage life, and individuals' income is always high enough to allow the mortgage payment and a minimum consumption.

Our main goals are the following:

1) To measure to what extent individuals strategically default in the laboratory in comparison to our theoretical benchmark, and why. Given each combination of initial state variables faced by the experimental subject, we compute the theoretically optimal (i.e. expected utility maximizing) consumption and default choices and compare them to the observed actions. We control for subjects' risk aversion, cognitive ability, expectations on future house prices and income, moral and social norm concerns and other socio-demographic variables to understand which individual characteristics are linked to default behavior.

2) To test the efficacy of economic incentives aimed at decreasing the incidence of strategic defaults. We do this in two treatments. While in the baseline treatment the defaulter can walk away from the mortgage without having to pay anything back after returning the house, in Treatment 1 (T1) we allow for the possibility of recourse by the lender: with a positive probability, the defaulter must repay the part of the mortgage debt not covered by the collateral. In Treatment 2 (T2), we introduce a cash reward granted to homeowners only once the mortgage has always been serviced up to a certain period, in the spirit of Edmans' (2010) Responsible Homeowner (RH) Reward. Edmans' (2010) argues that a contingent incentive would be less costly and much more effective than other solutions (as mortgage principal reductions) to solve the problem of strategic default. ${ }^{4}$ There is ample evidence in the experimental literature that individuals like and respond more strongly to rewards (Lazear, 2000, among others).

\footnotetext{
${ }^{1}$ Besides, strategic default could be contagious: people walking away from their house in a certain area could further depress house prices and decrease the "stigma" attached to default in that area, thus leading to more people walking away, in what would become a vicious circle (Bradley et al., 2015, and Goodstein et al., 2017).

${ }^{2}$ Using an alternative definition, however, $71 \%$ of defaulters would be able to reach a subsistence level of consumption if they met the mortgage payments. For Loan To Value (LTV) ratios higher than $90 \%$, estimates of strategic default range from $41 \%$ to $76 \%$ of total default (Gerardi et al., 2018).

${ }^{3}$ Guiso et al. (2013) ask some questions on social and moral concerns in their survey. However, the default decision is also the answer to a question ("If the value of your mortgage exceeded the value of your house by $50 \mathrm{~K}[100 \mathrm{~K} / 150 \mathrm{~K}]$ would you walk away from your house (i.e., default on your mortgage) even if you could afford to pay your monthly mortgage?"). Respondents' declarations could well differ from their real actions.

${ }^{4}$ The RH Reward was implemented in the United States by the investment firm Loan Value Group, LLC. Starting in 2010, a selected group of about 20,000 underwater homeowners were invited to sign up to the program (for free) and were promised cash rewards upon timely payments of their mortgage. According to an LVG's press release in 2013 (http://www.loanvaluegroup.com/news/130611_media_coverage.html, accessed 07/24/2018), the program has
} 
Our theoretical model of optimal default shares some characteristics with the dynamic equilibrium models of Campbell and Cocco (2015); Corbae and Quintin (2015), and Chatterjee and Eyigungor (2015). ${ }^{5}$ As in those contributions, mortgage default is the rational choice of a utility-maximizing homeowner facing income and house value uncertainty. Differently from these theories that endogenize the mortgage market, however, we build a partial equilibrium model that takes mortgage conditions as given and focuses on the individual decisions of mortgage payment, homeownership and consumption/saving over time. Our parsimonious set-up allows us to conduct an economic experiment on borrowers' behavior in the lab. Recently, Schelkle (2018) finds that a theoretical model in which mortgage default is triggered by the joint occurrence of negative house equity and a negative shock to income is more consistent with the empirical evidence than a traditional frictionless "option-theoretic" model of default. ${ }^{6}$ Our experiment is suited to testing this so-called "double trigger" hypothesis.

Economic experiments exploring dynamic consumption/saving decisions under uncertainty similar to the one presented in this paper find that individuals do not generally behave optimally (according to the standard life-cycle model), and conclude that people are "boundedly rational" (see Ballinger et al., 2003; Carbone and Hey, 2004; Hey and Dardanoni, 1988, among others)..$^{7}$ Despite this gap between observed and optimal behavior, though, the intertemporal optimization model does succeed in predicting behavioral changes as a result of changes in the parameter values, i.e. in the comparative statics. In our experiment, we focus our attention more on the discrete choice of default rather than on consumption/saving behavior, and we analyze the effect of different policies meant to decrease strategic default. It is found that more optimal behavior can be reached with some learning (Ballinger et al., 2003; Brown et al., 2009). Following this result, each participant of our experiment goes through five cycles of the decisions in a mortgage life so that they can accumulate some experience in this kind of choices.

Default behavior has also previously been studied in the lab. Brown et al. (2016) use an experimental setting to analyze default behavior and social norms in an economic crisis. To this end, they implement a one shot prisoner's dilemma in which the ability to cooperate is stochastic, thus creating fundamental as well as strategic default. Trautmann and Vlahu (2013) model the coordination game between two borrowers, who have to decide whether to repay their loan or to strategically default under different expectations on the bank's strength and on the borrowers' repayment capacity. Differently from these studies, our experiment focuses on the intertemporality of the individual repayment decision, and on its link to saving/consumption choices, so that our experimental game is more similar to the one faced by actual homeowners. A closer experiment to ours is the one in Rabanal (2014), who tests in the laboratory a frictionless option-theoretic model of the strategic default decision under different asset value volatilities and with or without the existence of social interactions. In contrast to that work, however, we take into consideration the potentially important role played by an unemployment shock in the decision to default, and the fact that the ability and the willingness to pay the mortgage are strictly linked to one's consumption and saving choices.

Our results show that subjects correctly default in the initial periods of a mortgage life and consume increasingly close to optimal with the game repetition. In particular, the combination of a low house price shock and an unemployment spell is an important trigger of default, coherently with the "double trigger" hypothesis mentioned above. Despite the fact that in our environment there does not exist any social stigma nor any serious consequences for not paying one's debt, however, experiment participants default much less than optimal: the observed default rate is about half the one predicted by the theory. Individuals' perception of the social norm in the experiment seems to play a role in explaining this deviation, while more general moral and social concerns do not significantly affect the default decision: an indication, perhaps, that individuals' answers to survey questions are not always good predictors of their actions. Other individual characteristics, as risk aversion and cognitive ability, do not significantly affect the likelihood of default. Both the treatment introducing a $50 \%$ probability of recourse and the treatment offering a Responsible Homeowner Reward at mid-mortgage life are significantly effective in discouraging default, in line with the theory. In fact, the reduction in default observed in the Responsible Homeowner Reward treatment is proportionally higher than what would be predicted by our theory. Both treatments are especially effective for individuals with low income facing deep negative equity, again an indication that income shocks play a potentially important role. Last, in contrast to the intertemporal consumption/saving decisions observed in the laboratory for subjects who do not hold any debt, in our experiment homeowners under-consume in the first periods of life, an indication that they are "cautious" when indebted with the mortgage, even if this debt was exogenously imposed on them.

In the next section we describe our model of the mortgage default decision, and in Section 3 we obtain its theoretical predictions. In Section 4 we describe the experimental design and procedure. Section 5 reports the main results and Section 6 includes a discussion and conclusions.

been successful in lowering late-stage delinquency rates (90 days or more) of participating veterans and serving military by more than $45 \%$ compared to control groups.

${ }^{5}$ Another strand of the literature analyzes the macroeconomic effects of default: Jeske et al. (2013); Magill and Quinzii (2015) and Lambertini et al. (2017), among others.

${ }^{6}$ An early example of an "option-theoretic" model of mortgage default is Kau et al. (1994). More recently, Deng et al. (2000) find that the option model can explain default behavior only by assuming the existence of default transaction costs, and enough heterogeneity across borrowers.

${ }^{7}$ There also exists an emerging literature on laboratory housing market experiments, that mainly focuses on house price bubbles and busts (Bao and Hommes, 2015; Huber et al., 2018; Ikromov and Yavas, 2012). 


\section{A model of mortgage default}

The dynamic problem starts at $t=1$ when the household has already bought a house and acquired a mortgage, and lasts for the whole duration of the mortgage, until $t=T$, the period after the last payment.

\subsection{Individual preferences and endowments}

The household receives utility from nondurable consumption $c$ and housing service flows, which we assume proportional to the size $\bar{h}$ of the house owned or rented. The momentary utility function is the following:

$$
u(c, H)=\log (c-\underline{c})+\log \left(\theta_{H} \bar{h}\right)
$$

where $\underline{c}$ is a minimum consumption level, $\theta_{H}=\theta_{1}$ if the agent owns a house $(H=1)$, and $\theta_{H}=\theta_{0}<\theta_{1}$ if the agent rents $(H=0){ }^{8}$ To simplify decisions, we assume only one house size for both owners and renters. Our preferences specification implies that the utility from owning a house is higher than the utility from renting it. This assumption aims at capturing the emotional attachment to one's home, the decreased uncertainty for not having to depend on landlords' decisions, and financial (e.g. tax) benefits that owning a house might provide, which we do not explicitly model. ${ }^{9}$ Assuming that owning provides more utility than renting implies a higher cost of default and is coherent with the empirical evidence that only a small percentage of underwater homeowners decide to default on their mortgage. ${ }^{10}$

Agents bought a house of total value $\bar{h} P^{I}$ for which they contracted a mortgage characterized by a series of constant mortgage payments $m$ and mortgage principals $\left\{M_{t}\right\}_{t=1}^{T}$. The downpayment for the house has already been paid at the beginning of the decision periods, and corresponds to a fraction $\lambda$ of its value. Denoting with $r^{m}$ the borrowing interest rate, mortgage payments are given by:

$$
m=\frac{r^{m}}{1-\left(1+r^{m}\right)^{-(T-1)}}(1-\lambda) \bar{h} P^{I}
$$

The mortgage principal at the beginning of each period $t$ (pre-payment) corresponds to the following:

$$
M_{t}= \begin{cases}(1-\lambda) \bar{h} P^{I}\left(1+r^{m}\right) & \text { for } t=1 \\ \left(M_{t-1}-m\right)\left(1+r^{m}\right) & \text { for } t=2, \ldots, T\end{cases}
$$

It is simple to verify that $M_{T}=0$.

At every period, the agent can be employed or unemployed, receiving labor income $y^{H}$ and $y^{L}$ respectively, where $y^{L}$ can represent unemployment benefits paid by the state. Employment shocks follow a Markov chain with transition probabilities denoted by $p_{i j}=\operatorname{Pr}\left\{y_{t+1}=y^{j} / y_{t}=y^{i}\right\}$ for every $i, j \in\{L, H\}$.

Moreover, each period the household receives one of two possible house price shocks, $P_{t} \in\left\{P^{L}, P^{H}\right\}, P^{L}<P^{H}$, with a stochastic distribution also described by Markov transition probabilities $q_{i j}=\operatorname{Pr}\left\{P_{t+1}=P^{j} / P_{t}=P^{i}\right\}$ for every $i, j \in\{L, H\}$. We are interested in analyzing situations in which agents are deeply indebted and house prices fall: that is why we assume that both $P^{L}$ and $P^{H}$ are lower than the initial price $P^{l}$ at which the house has been acquired.

Households can save through a risk-free asset $a_{t}$ which pays a known gross interest rate $R$, constant over time. They do not have any source of borrowing other than the mortgage $\left(a_{t} \geq 0\right)$.

\subsection{Household's choices}

At each period, homeowners decide how much to consume/save, and one among the following three options:

1) Keep the house and make the mortgage payment, with budget constraint:

$$
a_{t+1}=y_{t}+a_{t} R-c_{t}-m
$$

2) Sell the house and pre-pay the mortgage debt, incurring a transaction cost $\phi$ proportional to the house value, and having to rent from that period on until the end of the time horizon, $T$. This strong assumtion that households cannot buy a new house is computationally convenient and follows Campbell and Cocco (2015) and Corbae and Quintin (2015). In this case, the budget constraint is:

$$
a_{t+1}=y_{t}+a_{t} R-c_{t}+\bar{h} P_{t}(1-\phi)-M_{t}-\bar{h} P_{t}^{r}
$$

where $P_{t}^{r}$ denotes the house rental rate.

\footnotetext{
${ }^{8}$ Davis and Ortalo-Magné (2011) find that the expenditure share on housing is constant across time and U.S. metropolitan areas, thus justifying a separable log utility function. A similar specification of preferences can be found in Iacoviello and Pavan (2013) and Corbae and Quintin (2015), among others.

${ }^{9}$ Corbae and Quintin (2015); Schelkle (2018) and Kaplan et al. (2019) are recent examples of models incorporating this hypothesis.

${ }^{10}$ For instance, Gerardi et al. (2018) consider attachment to one's home one of the possible reasons why many homeowners decide to continue with the mortgage payment despite facing significant financial hardship.
} 
3) Default on the mortgage, paying a cost $\Psi$ in the period of default, and renting a house for the rest of the decision periods, with budget constraint:

$$
a_{t+1}=y_{t}+a_{t} R-c_{t}-\Psi-\bar{h} P_{t}^{r} .
$$

The rental rate $P_{t}^{r}$ is assumed to be a fixed percentage of the house price, $P_{t}^{r}=\omega P_{t}$ at every $t .{ }^{11}$ Thus, renters face uncertainty on employment status and rental prices, and only choose how much to consume/save.

In the baseline model (denoted by T0) we assume that, in the case of default, the mortgage lender seizes the house but has no recourse to the household's assets or labor income. A second version of this model (T1) allows for a positive probability $\pi$ that the lender obtains a deficiency judgment and forces the defaulter to pay the debt not covered by the collateral. The resolution of the deficiency judgment is known in the period subsequent to the default period and, in that case, the household must pay its debt in constant installments over the rest of its life.

A third version of the model (T2) introduces a Responsible Homeowner Reward in the form of a prize $\$$ to be given to the household that served its mortgage installments up to a period $\tau<T$.

The agent's objective function is equal to the expected discounted sum of the utility functions:

$$
E_{1}\left[\sum_{t=1}^{T} \beta^{t-1} u\left(c_{t}, H_{t}\right)\right]
$$

where $\beta \leq 1$ denotes the discount factor and $E_{1}$ is the expectations operator in period 1 . The household starts the last period free of mortgage debt, and can decide to keep the house or sell it. For the sake of simplicity, terminal housing wealth does not provide utility in the model.

The problem can be written and solved recursively using numerical methods. ${ }^{12}$ The dynamic problem solution for a homeowner consists of the policy functions $c_{t}^{o}\left(a_{t}, y_{t}, P_{t}\right), a_{t+1}^{o}\left(a_{t}, y_{t}, P_{t}\right), I_{t}^{o s d}\left(a_{t}, y_{t}, P_{t}\right) \in\{$ own, sell, default $\}$ for consumption, assets and the discrete decision of paying the mortgage and keeping the house, selling or defaulting respectively. Renters only choose consumption $c_{t}^{r}\left(a_{t}, y_{t}, P_{t}\right)$ and assets $a_{t+1}^{r}\left(a_{t}, y_{t}, P_{t}\right)$. In the model with a positive probability of recourse (T1), the house price $P_{s}$ and the default period $s$ fully determine the value of negative house equity and thus the constant installment to be paid in the case of being punished. The latter is therefore an additional state variable entering the policy function of the renter who previously defaulted.

\section{Model parameterization and predictions}

We parameterize our model with the experiment in mind: parameter values are to match some basic features of the housing and mortgage market at the beginning of and during the Great Recession, but are also to be easy to communicate and explain to subjects. Moreover, we parameterize the model so that it predicts a high percentage of default, given initial conditions. This is done on purpose, because we are interested in creating an environment in which individuals should strategically default if rational in terms of our model.

A complete list of the parameter values used for the solution and simulation of the theoretical model can be found in Table 1. Decisions are taken over a total of 10 periods, the discount factor is set equal to 1 and the risk-free asset bears no interest. ${ }^{13}$ The household has acquired a house of total value $\bar{h} P^{I}=40$, corresponding to four times the labor income $y^{H}=10$ of an employed agent. The initial Loan-To-Value ratio is set equal to 85\%, while the average Loan-To-Income (LTI) ratio at origination computed in the steady state of the income distribution is 3.6. A mortgage interest rate of $4 \%$ generates a constant mortgage installment of 4.57 to be paid in each of the first nine periods. This corresponds to an average Mortgage payment To Income (MTI) ratio of $48.5 \%$ in the steady state. These measures roughly match the pre-crisis mortgage debt ratios, while keeping numbers as simple as possible. ${ }^{14}$

We set the persistence of employment to be equal to 0.90 . If unemployed, the agent receives an income $y^{L}=6$, and her probability of finding a job is equal to $60 \%$. These numbers reflect an "economic crisis" situation, with an unemployment rate of over $14 \%$ in the steady state. Note that, with an income $y^{L}$, the unemployed agent can afford the mortgage payment and the minimum consumption level $\underline{c}=0.5$, even when holding no assets.

Reflecting the crisis situation, the two shocks to house prices are such that home values can fall by $40 \%$ (when $P^{L}$ is realized) or by $20 \%$ (when $P^{H}$ is realized) with respect to the original value. We set the persistence of both these shocks to

\footnotetext{
11 Davis et al. (2008) find that from 1960 to 2008 the rent-price ratio has been about 5\%, with the exception of the house price boom period, in which it fell to 3.5\%. We follow Corbae and Quintin (2015) in fixing this ratio at its former level for the period post- house price bubble. Alternative approaches are those in Campbell and Cocco (2015) and Kaplan et al. (2019), that model the rental price as a function of current and expected future house prices, or in Schelkle (2018), where rents are fixed.

12 See Appendix A for the formalization of the problem in recursive formulation and a brief description of the solution computation.

13 This is done to simplify the problem as much as possible for the subjects, as in Meissner (2016) and Ballinger et al. (2003), among others. A positive interest rate on savings would just slightly modify the consumption pattern, introducing an additional saving motive in the first periods, with barely no impact on the default decision. On the other hand, introducing impatience would generate a strong incentive for all agents to default in the first period. We prefer a parameterization that allows for some heterogeneity in default behavior.

14 Campbell and Cocco (2015), for example, document an average LTV of about 75\% (excluding second mortgages), average LTI ratios higher than 3.5 starting in the 2000s, and average MTI ratios between $30 \%$ and $35 \%$ in the same period (again, omitting second mortgages).
} 
Table 1

Parameter values.

\begin{tabular}{|c|c|c|c|}
\hline Parameter & Value & Description & Explanation/Source \\
\hline$T$ & 10 & Decision periods & Experiment time constraint \\
\hline$\beta$ & 1 & Discount factor & Experiment simplification \\
\hline$\theta_{1}$ & 1 & Utility weight on owned house & As in Iacoviello and Pavan (2013) \\
\hline$\theta_{0}$ & 0.8 & Utility weight on rented house & \\
\hline$\underline{c}$ & 0.5 & Minimum consumption level & To prevent subjects from consuming 0 \\
\hline$\overline{\bar{h}}$ & 2 & House size & Discretionary value \\
\hline$a_{0}$ & 0.5 & Initial asset level & Discretionary value, low \\
\hline$w$ & 0.05 & Rental rate, as \% of house price & $\begin{array}{l}\text { As in Davis et al. (2008) } \\
\text { and in Corbae and Quintin (2015) }\end{array}$ \\
\hline$\phi$ & 0.05 & $\begin{array}{l}\text { House transaction cost when selling, } \\
\text { as \% of house price }\end{array}$ & National Association of Realtors (2005) \\
\hline$R$ & 1 & Risk-free gross interest rate & Experiment simplification \\
\hline$\lambda$ & 0.15 & House downpayment & High LTV ratio of $85 \%$, between Corbae and Quintin (2015) and Schelkle (2018) \\
\hline$r^{m}$ & 0.04 & Mortgage interest rate* & $\begin{array}{l}\text { Average DTI of } 48 \% \text {, similar to } \\
\text { Gerardi et al. (2018) and Schelkle (2018) }\end{array}$ \\
\hline$\Psi$ & 1 & Default cost & $\begin{array}{l}\text { Experiment simplification, about } 10 \% \\
\text { of average income }\end{array}$ \\
\hline$y^{H}$ & 10 & Income if employed & LTI of 3.5, Campbell and Cocco (2015) \\
\hline$y^{L}$ & 6 & Income if unemployed & $\begin{array}{l}60 \% \text { replacement rate of unemployment } \\
\text { insurance, as in Schelkle (2018) }\end{array}$ \\
\hline$p_{H H}$ & 0.90 & Probability of staying employed & Discretionary simple values, high \\
\hline$p_{L L}$ & 0.40 & Probability of staying unemployed & Unemployment rate of $14.3 \%$ in steady state \\
\hline$P^{L}$ & 12 & Low house price realization & Discretionary simple values, in accordance \\
\hline$P^{H}$ & 16 & High house price realization & with Case-Shiller Home Price Index (see text) \\
\hline$P^{l}$ & 20 & Initial house price & $\begin{array}{l}\text { Home value at origination about } 4 \text { times } \\
\text { the average income }\end{array}$ \\
\hline$q_{H H}$ & 0.6 & Persistence of high house price & Discretionary values, experiment \\
\hline$q_{L L}$ & 0.6 & Persistence of low house price & simplification \\
\hline$\pi$ & 0.5 & Probability of punishment in $\mathrm{T} 1$ & Experiment simplification \\
\hline$\$$ & 5 & Prize in $\mathrm{T} 2$ & Based on LVG's Responsible Homeowner \\
\hline$\tau$ & 5 & Prize payment period & Reward (see text) \\
\hline
\end{tabular}

*Note: With this interest rate, the mortgage payment $m$ is equal to 4.57 from period 1 to 9 .

be $0.6 .{ }^{15}$ These parameters create a very uncertain economic environment in which house equity is negative in the first two periods of the life of the mortgage, irrespective of the house price realization.

We set a probability $\pi=50 \%$ of punishment in model T1. In T2, the Responsible Homeowner Reward is set equal to 5 (or about $15 \%$ of the initial mortgage value). The reward is paid in period 5 to the mortgagors that have been current on their payments through the first 4 periods, that is, the periods in which the house equity is possibly negative. ${ }^{16}$

Given these parameter values, we can solve for the model policy functions, which tell us the optimal choices for each combination of initial state variables characterizing the household (age, initial assets, employment status, etc.) and simulate the optimal decisions corresponding to each initial state.

As an illustration, Fig. 1 shows the simulated choices of four selected agents, one for each initial combination of the shocks in period 1. Panel A in the figure shows the income and house price realizations over the ten decision periods, together with house equity and default behavior (in the right axis) for each of the three treatments. If house equity is equal to zero in the graph, it is because the agent defaulted or sold the house.

Default in the model is always strategic and happens in the first periods of the mortgage life, characterized by (possibly deep) negative equity in a crisis environment where prices fall with respect to the purchase price. In the baseline treatment in fact, only the agent receiving the higher realizations of both income and price shocks does not default in the first period. This type of agent could default later on, if becoming unemployed and receiving the lower house price shock (bottom right chart in Fig. 1, Panel A). In this sense, the model predictions are consistent with the so called "double trigger" hypothesis, according to which default is triggered by the joint occurrence of negative equity and a bad life event such as unemployment (Schelkle, 2018). The existence of a recourse probability deters strategic default for deeply negative house equity (top charts in Fig. 1, Panel A), given the harsher punishment of having to pay back the debt in excess of the market house value. This punishment is not effective for low negative equity (as in the bottom left chart of Panel A, for an individual with low income but high house price in $t=1$ ). In some cases (as in the top left chart, if unemployment persists up to the second period), the positive probability of recourse has the effect of delaying the default decision to periods characterized by lower negative equity. The existence of a Responsible Homeowner Reward, on the other hand, is a strong enough incentive to keep

${ }^{15}$ These numbers are in accordance with the S\&P/Case-Shiller 20-City Composite Home Price Index, that fell by about $30 \%$ between April 2006 and May 2009.

${ }^{16}$ The LVG's Responsible Homeowner Reward could pay up to 30\% of the mortgage principal to underwater homeowners that made their payments on time during 3 to 5 years (http://closewithpam.com/underwater-solutions/responsible-homeowner-reward-rh-reward/, accessed July 23, 2018 at 12 p.m.). 


\section{Panel A: House equity and optimal default decisions}
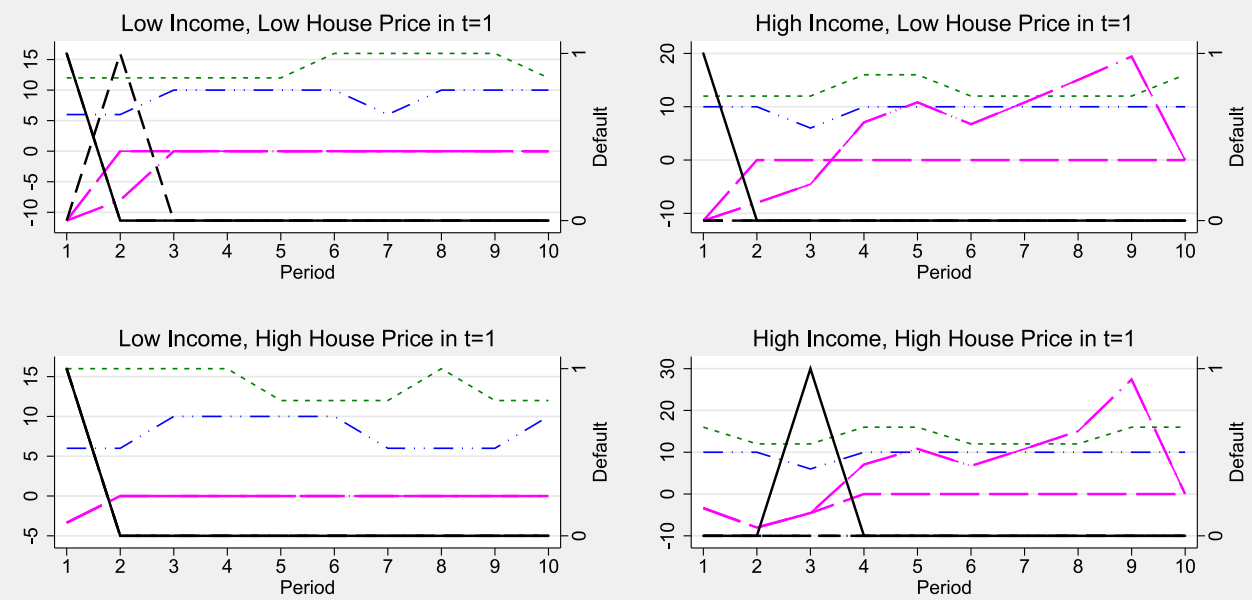

\begin{tabular}{|c|c|c|c|c|}
\hline$-\cdots-$ & Income & & House price & \\
\hline$-\div$ & H. equity TO & -1 & H. equity $T 1$ & $-\cdots-H$. equity $T 2$ \\
\hline & Default T0 & --- & Default T1 & -- Default T2 \\
\hline
\end{tabular}

Panel B: Optimal consumption decisions
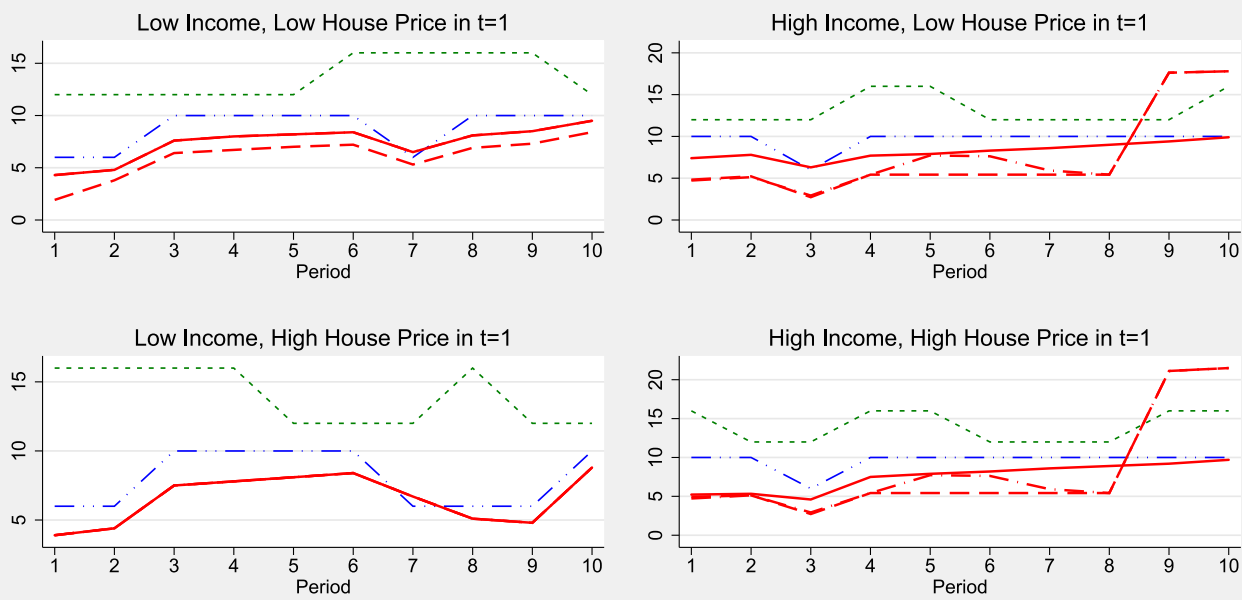

\begin{tabular}{|lllll|}
\hline$-\cdots-\cdots$ & Income & $\cdots \cdots \cdots$ & House Price \\
& Cons. T0 & ---- & Cons. T1 $\quad-\cdots,-$ Cons. T2 \\
\hline
\end{tabular}

Fig. 1. Simulated optimal choices for each possible combination of shocks in period 1 . Note: Default takes the value of 1 if the household defaults, 0 otherwise, shown in the right axis of Panel A. Cons. $=$ consumption; H. equity $=$ House equity $\left(M_{t}-\bar{h} P_{t}\right.$ in period $\left.t\right)$. T0 $=$ Baseline model; T1 $=$ Model with $50 \%$ probability of recourse; T2 = Model with Responsible Homeowner Reward. Income and house price shocks from period 2 on are randomly drawn according to their stochastic processes. For the low income, low house price shock combination (top left of each panel), T2 and T0 choices coincide. For the low income, high house price shock combination (bottom left of each panel), optimal behavior does not differ among treatments. For the high income, low house price shock combination, in T1 and T2 the household never defaults (top right of panel A). The same happens for the high income, high house price shock combination (bottom right of panel A). 
Table 2

Optimal default decision in period 1 as a function of initial conditions, for each of the three theoretical models.

\begin{tabular}{llll}
\hline Initial Condition & T0 & T1 & T2 \\
\hline$\left(y^{L}, P^{L}\right)$ & Strategic default & Keep the house & Strategic default \\
$\left(y^{H}, P^{L}\right)$ & Strategic default & Keep the house & Keep the house \\
$\left(y^{L}, P^{H}\right)$ & Strategic default & Strategic default & Strategic default \\
$\left(y^{H}, P^{H}\right)$ & Keep the house & Keep the house & Keep the house \\
\hline
\end{tabular}

T0 = Baseline model; T1 = Model with 50\% probability of recourse; T2 = Model with a Responsible Homeowner Reward.

the house for those receiving a higher income, but not for the unemployed in the model. Table 2 summarizes the optimal default decisions in period 1 as a function of the combination of employment and house price shocks in that period, for each of the three theoretical models.

As can be seen in Fig. 1, Panel B, the optimal consumption pattern closely follows the income path: the possibility of consumption smoothing is limited in the model by the fact that it is not possible to borrow (apart from the mortgage). In general, agents should try to build a buffer stock of savings in the first periods, and then dissave in the last years. Depending on the combination of shocks, the household that held on to its house through the first four periods of (possibly) negative equity should sell it sometime in the second half of the life cycle.

We are interested in studying whether this kind of behavior can be observed in the laboratory, especially whether subjects' decisions are significantly different under the three treatments.

\section{Experimental design and procedure}

The experimental design implements the assumptions and the parameterization of the theoretical model described above.

Following common practice (see for example Brown et al., 2009, or Meissner, 2016), terms as "income shocks" and "utility" are avoided, and substituted by the more user-friendly "token income realizations" and "points". Instead of "consumption" we use the more neutral term "points conversion" and we never mention the term "debt" or "savings" in the experiment, but rather "installments to pay" and "accumulated points", respectively. The house owned is defined as "(long-lived) asset A", while the house rented is called "(short-lived) asset B", an asset that you must buy every period. We prefer a neutral framing to avoid assigning any kind of moral judgment to individuals' decisions.

At the beginning of the experiment, participants are given fifteen minutes to read the instructions. The experimenter then reads the instructions aloud. ${ }^{17}$

Each individual plays five subsequent life cycles. In each of the first four cycles, each participant is assigned a different initial combination of house price and income shocks in the first period $(t=1)$ among the four possible ones: $\left(y^{L}, P^{L}\right),\left(y^{H}\right.$, $\left.P^{L}\right),\left(y^{L}, P^{H}\right)$ and $\left(y^{H}, P^{H}\right)$. This allows subjects to accumulate experience in all possible initial scenarios before playing in the fifth life a repetition of one of the first four combinations of initial state variables (only in period 1). In each life, the income and house price realizations from period 2 on are randomly drawn for each subject according to their stochastic process. According to Brown et al. (2009), subjects learn to behave almost optimally within four life cycles. We have introduced an additional life cycle in our design to allow for subjects' further experimentation. However, a higher number of lives would have come at the cost of delaying the end of the session, so we have looked for a balance between learning opportunities and experiment duration. Subjects are told that they will be paid at the end of the experimental session a money amount converted from the total points earned in one, randomly chosen, sequence of the first four, and the last sequence, according to the total sum of points earned in these two sequences. ${ }^{18}$ The points earned each period depend on the tokens converted in that period and on whether the individual owns or rents a house, according to the parameterized utility function presented in the above sections, as shown in Table 3, which is also the numerical table given to subjects in the instructions. ${ }^{19}$

At the beginning of each experimental period, subjects observe their token income realization, the tokens accumulated from the former period and the corresponding initial resources, the value of their asset $\mathrm{A}$, information about what they have to pay and the tokens available after payments. If the subject still owns a house, the computer screen is divided into three parts and the above information is shown for each of the three options (paying the mortgage, selling and defaulting). The program allows participants to experiment with numbers as long as they need before submitting their actual choice. For each option, individuals can input a desired number of tokens to convert (their consumption choice), and the screen shows the corresponding points (the utility) they would earn in that period together with the accumulated tokens (their savings)

\footnotetext{
17 The instructions translated into English can be found as supplementary material of this article. The Spanish version is available from the authors upon request.

18 Subjects receive the information on the randomly selected sequence only at the end of the session. In this way, we promote experimentation in the first four lives and make the fifth one more payoff-relevant. This design aims at minimizing both the effect of possible fatigue and wealth effects.

19 The parameterized utility function of the theoretical model is multiplied by 10000 and added to 3000 , to be more easily readable.
} 
Table 3

Numerical table of the "Points Function".

\begin{tabular}{|c|c|c|}
\hline Consumption & Points If Owning & Points If Renting \\
\hline 0.5 & -266379 & -268610.4 \\
\hline 1 & 3000 & 768.6 \\
\hline 1.5 & 9931.5 & 7700 \\
\hline 2 & 13986.1 & 11754.7 \\
\hline 2.5 & 16862.9 & 14631.5 \\
\hline 3 & 19094.4 & 16862.9 \\
\hline 3.5 & 20917.6 & 18686.2 \\
\hline 4 & 22459.1 & 20227.7 \\
\hline 4.5 & 23794.4 & 21563 \\
\hline 5 & 24972.2 & 22740.8 \\
\hline 5.5 & 26025.9 & 23794.4 \\
\hline 6 & 26979 & 24747.5 \\
\hline 6.5 & 27849.1 & 25617.6 \\
\hline 7 & 28649.5 & 26418.1 \\
\hline 7.5 & 29390.6 & 27159.1 \\
\hline 8 & 30080.5 & 27849.1 \\
\hline 8.5 & 30725.9 & 28494.5 \\
\hline 9 & 31332.1 & 29100.7 \\
\hline 9.5 & 31903.7 & 29672.3 \\
\hline 10 & 32444.4 & 30213 \\
\hline 10.5 & 32957.3 & 30725.9 \\
\hline 11 & 33445.2 & 31213.8 \\
\hline 11.5 & 33910.4 & 31679 \\
\hline 12 & 34354.9 & 32123.5 \\
\hline 12.5 & 34780.5 & 32549.1 \\
\hline 13 & 35188.8 & 32957.3 \\
\hline 13.5 & 35581 & 33349.5 \\
\hline 14 & 35958.4 & 33726.9 \\
\hline 14.5 & 36322 & 34090.6 \\
\hline 15 & 36673 & 34441.5 \\
\hline
\end{tabular}

they would own at the beginning of the next period. They are then asked to make a choice depending on their initial status as a homeowner or, later in the game once they sold the house or defaulted, as a renter.

We run three treatments, each corresponding to the three theoretical models introduced above. We refer to model T0 as the Baseline treatment, to model T1 as the Recourse treatment and to model T2 as the Responsible Homeowner (RH) Reward treatment.

In each period of Life 5, we ask subjects which income and house price realization they expect to receive in the next period, thus eliciting their individual beliefs. After the end of the experiment, we conduct a risk aversion test (SabaterGrande and Georgantzís, 2002) and the Differential Aptitude Test - Abstract Reasoning (DAT-AR) to measure cognitive ability (Bennett et al., 1974). ${ }^{20}$ Both tests are incentivized, with an average earning of 5.2 and 4.4 euro respectively. Last, individuals are asked to fill in a questionnaire on their attitude towards debt repayment obligations both in the laboratory and in real life, thus retrieving moral and social norm considerations. The questionnaire can be found in Appendix B.

We run six sessions (two per treatment) in December 2016, with 76-80 participants per treatment, for a total of 235 subjects, recruited using ORSEE (Greiner, 2015) among students and senior students of the Universitat Jaume I of Castellón (Spain). Of these, $74 \%$ were economics/business students and 22\% were engineering students, with the rest coming from other fields of study. Experiments were programmed in Z-Tree (Fischbacher, 2007) and run in the Laboratory for Experimental Economics (LEE) at the same university. The average total amount earned was of 36.7 euro, and sessions lasted about four hours including payment.

\section{Experimental results}

\subsection{Descriptive statistics}

Table 4 presents descriptive statistics for the socio-demographic characteristics, tests' results and answers to the questionnaire of the participants to the experiment. Subjects are 23 years old on average, $43 \%$ are female, and $20 \%$ of them have no previous laboratory experience. The mean number of correct answers to the DAT-Abstract Reasoning test is 23 out of 40 total questions, in line with the average calculated for the Spanish population of a similar age (see Cordero and

20 The test by Sabater-Grande and Georgantzís (2002) was developed in our laboratory and is our standard measure of risk aversion. Using this test, Barreda-Tarrazona et al. (2011) obtain an estimate of a CRRA coefficient that is perfectly in line with the one estimated by Harrison et al. (2009) based on the more common Holt and Laury (2002) test. To measure cognitive ability, we adopt the Cordero and Corral (2006) Spanish adaptation of the original DAT. 
Table 4

Descriptive statistics.

\begin{tabular}{|c|c|c|c|c|c|c|}
\hline \multirow[t]{2}{*}{ Variable } & \multirow{2}{*}{$\begin{array}{l}\text { All Treatments } \\
\text { Mean }\end{array}$} & \multirow{2}{*}{$\begin{array}{l}\text { T0 } \\
\text { Mean }\end{array}$} & \multirow{2}{*}{$\begin{array}{l}\text { T1 } \\
\text { Mean }\end{array}$} & \multirow{2}{*}{$\begin{array}{l}\text { T2 } \\
\text { Mean }\end{array}$} & \multicolumn{2}{|c|}{ Kruskal-Wallis } \\
\hline & & & & & Chi 2 & $p$-value \\
\hline Age & 23.4 & 25.27 & 22.06 & 22.94 & 5.067 & 0.079 \\
\hline Female & $43 \%$ & $31 \%$ & $52 \%$ & $43 \%$ & 7.076 & 0.0291 \\
\hline DAT-AR correct answers & 23.4 & 22.41 & 24.13 & 23.71 & 1.737 & 0.4196 \\
\hline No lab experience & $20 \%$ & $20.2 \%$ & $23.7 \%$ & $15.8 \%$ & 0.767 & 0.6813 \\
\hline Risk aversion & $-0.07^{b}$ & $-0.11^{\mathrm{b}}$ & $0.07^{\mathrm{b}}$ & $0.04^{\mathrm{b}}$ & 1.131 & 0.5682 \\
\hline Endure very hard times & $1.7 \%^{\mathrm{a}}$ & $0 \%{ }^{\mathrm{a}}$ & $2.5 \% \mathrm{a}$ & $2.6 \% \mathrm{a}$ & 2.487 & 0.2883 \\
\hline Just make ends meet & $16.2 \%$ & $16.4 \%^{\mathrm{a}}$ & $20.2 \%^{\mathrm{a}}$ & $11.8 \% \mathrm{a}$ & idem & idem \\
\hline Live moderately well & $70.5 \% \mathrm{a}$ & $68.3 \% \mathrm{a}$ & $68.3 \% \mathrm{a}$ & $75 \%$ a & idem & idem \\
\hline Well off & $11.5 \%^{\mathrm{a}}$ & $15.19 \%{ }^{\mathrm{a}}$ & $8.86 \%$ & $10.5 \%$ & idem & idem \\
\hline People should pay (1-5) & 4.64 & 4.62 & 4.63 & 4.67 & 0.132 & 0.9362 \\
\hline People do pay $(1-5)$ & 2.87 & 3.06 & 2.76 & 2.78 & 4.709 & 0.0949 \\
\hline Feel morally obliged to pay $(1-5)$ & 4.46 & 4.49 & 4.48 & 4.39 & 1.261 & 0.5322 \\
\hline Sometimes justified not to pay (1-5) & 3.06 & 3.06 & 3.1 & 3.02 & 0.109 & 0.9471 \\
\hline Participants should have paid $(1-5)$ & 3.46 & 3.27 & 3.65 & 3.44 & 4.347 & 0.1138 \\
\hline Which \% do you believe have not paid? & 41.2 & 44.26 & 38.36 & 40.9 & 1.655 & 0.4371 \\
\hline Given $P^{L}$, expect $P^{H}$ & $46.5 \%^{\mathrm{a}}$ & $45 \%^{\mathrm{a}}$ & $48.5 \%$ & $45.9 \%$ & 0.982 & 0.6121 \\
\hline Given $P^{H}$, expect $P^{L}$ & $50.7 \%$ & $55.5 \%$ a & $54.4 \%^{\mathrm{a}}$ & $41.7 \% \mathrm{a}$ & 15.880 & 0.0004 \\
\hline Given $y^{L}$, expect $y^{H}$ & $83.1 \%$ & $80.1 \% \mathrm{a}$ & $87.8 \%$ & $81.7 \%$ & 3.452 & 0.178 \\
\hline Given $y^{H}$, expect $y^{L}$ & $9.3 \%{ }^{\mathrm{a}}$ & $11.3 \%^{\mathrm{a}}$ & $8.6 \%^{\mathrm{a}}$ & $8.1 \%^{\mathrm{a}}$ & 3.727 & 0.1551 \\
\hline Number of Obs. & 235 & 79 & 80 & 76 & & \\
\hline
\end{tabular}

Note: $\mathrm{T} 0=$ Baseline treatment; $\mathrm{T} 1=$ Recourse treatment; $\mathrm{T} 2=$ Responsible Homeowner Reward treatment. $P^{L}=$ Low House Price, $P^{H}=$ High House Price; $y^{L}=$ Low Income, $y^{H}=$ High Income. ${ }^{\text {a }}$ Frequency is reported; ${ }^{\mathrm{b}}$ Standardized variable, median is reported.

Corral, 2006). Given that the risk aversion index goes from a value of -1.66 corresponding to almost risk neutrality to about 2.25 for very high risk aversion, subjects in this experiment are only moderately risk averse (average risk aversion index of -0.07). Asked for the financial situation faced at home, the majority (70\%) answer that they live moderately well, but $16 \%$ live in families that only can make ends meet and almost $2 \%$ endure very hard times. There are no substantial differences in the composition of these characteristics among the three treatments, with the exception of the percentage of female participants, that is higher in the Recourse treatment (52\%) and lower in the Baseline treatment (31\%). ${ }^{21}$ Results of a Kruskal-Wallis test comparing the distributions of the three treatments are reported in the last two columns of the table.

Most individuals declare that people should pay their debts (average 4.64 "agree" on a Likert scale from 1 to 5 ) and also that they feel morally obliged to pay (4.46). At the same time, less people state that participants should have paid their debts in the context of this experiment (average 3.46 out of 5), and a non-trivial number of people agree that sometimes it is justified not to pay (average 3.06). Moreover, subjects believe that $41 \%$ of them did not pay their debts in the laboratory (which is about the correct percentage for the baseline but more than doubles the ratio of observed default in the treatments).

The beliefs about future house price and income realizations were collected only in the last life, after having experienced four full sets of sequences of these shocks. Individuals tend to be optimistic when receiving bad shocks, especially to income: of those faced with a low house price, $46.5 \%$ expect the house price to increase in the next period (the probability is of $40 \%$ ), while of those having received the low (unemployment) income, $83 \%$ believe that the next income realization will be higher, despite the fact that the odds of this event are only 60\%. A correct fraction of employed agents predict to fall into unemployment (about 10\%), while people underestimate the probability of high house prices repeating if their price is high in the current period (49.3\% against a theoretical $60 \%$ chance).

In the next two subsections, we analyze the discrete decisions of homeownership and default, while Section 5.4 describes consumption behavior in the experiment.

\subsection{The homeownership and default decisions}

For each period of each life, an experimental subject's observed default behavior and consumption choices can be compared to the ones predicted by the theory. Following the literature (Carbone and Hey, 2004; Meissner, 2016, among others), we compute optimal behavior in two different ways. First, given each subject's initial assets and exact same sequence of income and house price shocks realizations over life, we numerically solve for the optimal choices. We call this unconditionally optimal or simply optimal behavior. The second approach consists in computing the optimal theoretical choices for the combination of initial states (homeownership, assets, income and house price) characterizing the situation faced by each experimental subject at the beginning of each period, independently on whether her choices were optimal in the past. This is the conditionally optimal behavior, and "forgets" individual past departures from the theoretical choices.

21 In the subsequent analysis gender is only found to be relevant in the consumption decision, but not in the default decision. 


\section{T0 Baseline}

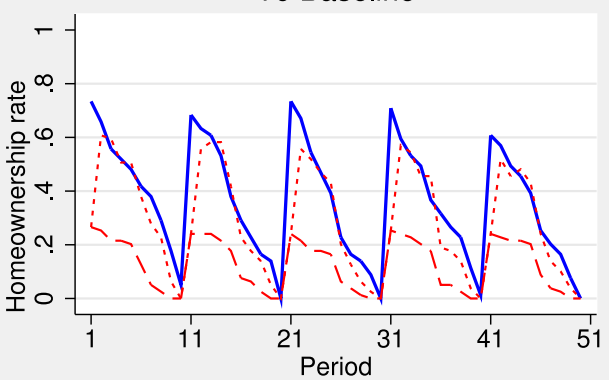

T1 Probability of Recourse

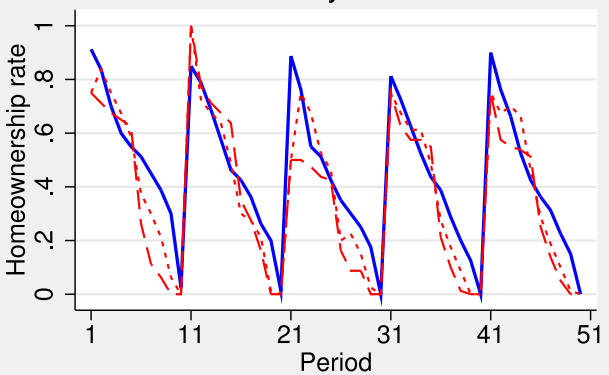

T2 Responsible Homeowner Reward

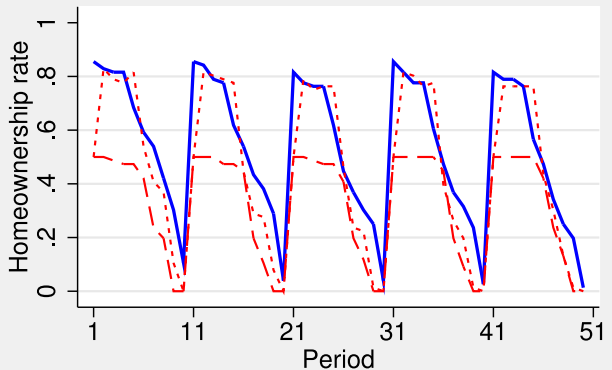

Fig. 2. Actual versus optimal homeownership rates, by treatment. Note: The homeownership rate is calculated as the percentage of individuals that pay the mortgage. In the horizontal axis, periods 1-10 correspond to the first life, periods $11-20$ to the second life, and so on up to period 50 .

We first present homeownership behavior over the five experimental lives. We then focus the attention on the decisions of the homeowners, especially on mortgage default.

We define the "homeownership rate" as the percentage of subjects who decide to pay the mortgage. Observed and optimal homeownership rates by period, life and treatment are shown in Fig. 2. In the baseline, about $60 \%$ to $73 \%$ of experiment participants decide to pay their mortgage installment in the first period, and homeownership declines at an approximately constant rate over the life. Despite being quite far from unconditionally optimal behavior (only $25 \%$ of individuals should stay on as homeowners in period 1 according to the theory), the observed homeownership tracks conditionally optimal behavior well. The two treatments succeed in increasing the percentage of people keeping their home in the first period to more than $80 \%$. The incentives put forward by the Responsible Homeowner Reward are clearly working, in the experiment as in the theory, in that individuals sell the house only after having received their "prize" in period 5 . Behavior is closer to optimality in treatment T1: introducing the probability of recourse is a quite effective deterrent of default especially in the first period (we will analyze this effect more in detail below). ${ }^{22}$

Given that all homeowners in our model face the discrete choice of paying the mortgage, selling or defaulting, we can count the number of occurrences in which the homeowners in the experimental data choose the correct option, in an unconditional as well as in a conditional sense. Results are presented in Table 5. Of all the homeowners that should make a particular choice (optimally or conditional on their states), the panels in the table show the percentage of those that actually make that choice in the experiment, comparing the first to the last life for all data and by treatment. The decision most often correctly taken is the mortgage installment repayment: about $90 \%$ of the subjects that should pay their mortgage do so, irrespective of the treatment. ${ }^{23}$ Experimental homeowners perform less well in the decisions of selling or defaulting: only about one quarter of those that should sell (or default) take that decision. If we do not take into account past departures

\footnotetext{
22 Note that, in the first period of each experimental session, lives 1, 4 and 5 are characterized by a balanced distribution over the four different "types" of initial shock combinations. Due to a programming mistake, however, in life 2, period 1, half of the subjects receive the $\left(y^{L}, P^{L}\right)$ shocks, $25 \%$ receive the $\left(y^{H}\right.$, $\left.P^{L}\right), 25 \%$ the $\left(y^{H}, P^{H}\right)$, and there are no individuals with $\left(y^{L}, P^{H}\right)$. Similarly, in the first period of life 3 , half of the subjects receive the $\left(y^{L}, P^{H}\right)$ shocks, $25 \%$ receive the $\left(y^{H}, P^{L}\right), 25 \%$ the $\left(y^{H}, P^{H}\right)$, and there are no individuals with $\left(y^{L}, P^{L}\right)$. This is the reason why in T1 the predicted homeownership rates in period 1 differ across lives: the theoretical homeownership rate is $100 \%$ in the second life, $50 \%$ in the third life, and $75 \%$ in each of the other lives (calculations can be derived from Table 2, given the initial distributions of shocks). Since there is no interaction between subjects in the experiment and the total number of types is approximately the same across each session, this programming mistake has no consequences for our analysis.

${ }^{23}$ This result is maintained if we restrict the analysis to the homeowners with negative house equity.
} 
Table 5

Percentage of homeowners' correct decisions.

\begin{tabular}{|c|c|c|c|c|}
\hline \multicolumn{5}{|l|}{ All Treatments } \\
\hline \multirow[t]{2}{*}{ Decision } & \multicolumn{2}{|l|}{ Optimal } & \multicolumn{2}{|c|}{ Cond. Optimal } \\
\hline & LIFE 1 & LIFE 5 & LIFE 1 & LIFE 5 \\
\hline Pay the mortgage & $91.9 \%$ & $86.9 \%$ & $91.3 \%$ & $88.4 \%$ \\
\hline Sell & $25.7 \%$ & $34.1 \%$ & $36.7 \%$ & $45.7 \%$ \\
\hline Default & $24.0 \%$ & $25.2 \%$ & $22.5 \%$ & $22.2 \%$ \\
\hline \multicolumn{5}{|l|}{ T0 Baseline } \\
\hline \multirow[t]{2}{*}{ Decision } & \multicolumn{2}{|l|}{ Optimal } & \multicolumn{2}{|c|}{ Cond. Optimal } \\
\hline & LIFE 1 & LIFE 5 & LIFE 1 & LIFE 5 \\
\hline Pay the mortgage & $88.2 \%$ & $85.3 \%$ & $90.4 \%$ & $89.0 \%$ \\
\hline Sell & $50.0 \%$ & $33.3 \%$ & $42.9 \%$ & $50.0 \%$ \\
\hline Default & $30.0 \%$ & $43.3 \%$ & $26.8 \%$ & $38.6 \%$ \\
\hline \multicolumn{5}{|l|}{ T1 Recourse } \\
\hline \multirow[t]{2}{*}{ Decision } & \multicolumn{2}{|l|}{ Optimal } & \multicolumn{2}{|c|}{ Cond. Optimal } \\
\hline & LIFE 1 & LIFE 5 & LIFE 1 & LIFE 5 \\
\hline Pay the mortgage & $91.2 \%$ & $87.0 \%$ & $90.9 \%$ & $86.3 \%$ \\
\hline Sell & $20.0 \%$ & $30.0 \%$ & $35.8 \%$ & $41.0 \%$ \\
\hline Default & $13.0 \%$ & $6.1 \%$ & $14.8 \%$ & $4.9 \%$ \\
\hline \multicolumn{5}{|c|}{ T2 Responsible Homeowner Reward } \\
\hline \multirow[t]{2}{*}{ Decision } & \multicolumn{2}{|l|}{ Optimal } & \multicolumn{2}{|c|}{ Cond. Optimal } \\
\hline & LIFE 1 & $\overline{\text { LIFE } 5}$ & LIFE 1 & LIFE 5 \\
\hline Pay the mortgage & $93.9 \%$ & $87.4 \%$ & $92.3 \%$ & $89.9 \%$ \\
\hline Sell & $24.0 \%$ & $40.0 \%$ & $33.0 \%$ & $47.4 \%$ \\
\hline Default & $21.0 \%$ & $13.2 \%$ & $20.0 \%$ & $11.9 \%$ \\
\hline
\end{tabular}

Note: Of all the homeowners that should make a particular choice (optimally or conditional on their states), the table shows the percentage of those that actually make that choice in the experiment.

from optimal behavior, however, in life 5 more than $45 \%$ of the subjects decide to correctly sell the house, given their actual state variables at the beginning of the period.

The baseline treatment presents the highest number of optimal defaulters: in the last life of T0, in fact, more than $43 \%$ of the homeowners that should strategically default on their mortgage do so. This is also the only treatment where some learning seems to take place in the default decision over lives, even if the increase in the percentage of correct defaulters between lives is only marginally significant (proportion test $z$-value $=-1.52, p$-value $=0.065$ ). The number of optimal defaults decreases in the treatments that incentivize the mortgage repayment, especially the one that introduces a positive probability of recourse: in the last life of T1, in fact, of the 33 subjects who should "walk away" from their mortgage at some point in time, only 2 do so correctly. The other 11 subjects that default in this treatment should have paid their mortgage installment to maximize their expected utility. Similarly, in the RH reward treatment, only 5 subjects default correctly, while 12 do so incorrectly. In the baseline, a higher number of subjects, 26 , default correctly, but the number of incorrect defaults, 9 , is similar. ${ }^{24}$ We can conclude that in the two treatments homeowners behave less optimally than in the baseline as far as the default decision is concerned. It appears that a further reduction in default beyond the theoretically expected one is produced by the introduction of these treatments.

In the case of default, conditionally and unconditionally optimal choices almost coincide, since most default should take place in the first period. Fig. 3 contrasts observed versus conditionally and unconditionally optimal default rates (calculated as the percentage of homeowners who default) in each experimental life and treatment. ${ }^{25}$ Default in the lab happens in the first periods of life, as optimal, even if in general subjects tend to default much less than optimal: for example, while the predicted default rate is approximately $75 \%$ in the first period of the baseline model, the default rate ranges between $25 \%$ and $38 \%$ in the experiment. ${ }^{26}$ The same pattern can be observed in treatments $\mathrm{T} 1$ and $\mathrm{T} 2$. The fact that optimal default

\footnotetext{
${ }^{24}$ On average, $17 \%$ of all the observed defaulters in treatment $\mathrm{T} 1$ (12\% in $\left.\mathrm{T} 2\right)$ are characterized by a value of the house equity higher than the selling cost minus the default cost, compared to only $6 \%$ in the baseline treatment. These individuals would be clearly better off selling their house. However, these irrational default choices decrease over lives in all treatments, almost disappearing in the last life.

${ }^{25}$ Again, notice that in $\mathrm{T} 1$ the predicted default rate is zero in the second life, 50\% in the third life, and $25 \%$ in each of the other lives (from Table 2 , taking into consideration the unbalanced distribution of initial shocks in lives 2 and 3).

${ }^{26}$ In general, subjects do not delay the decision of default to a later period: while conditionally optimal default rates range between $16 \%$ and $24 \%$ in the second period depending on the life, the observed default rates can be as low as $2 \%$ and not higher than $13 \%$ in that period.
} 


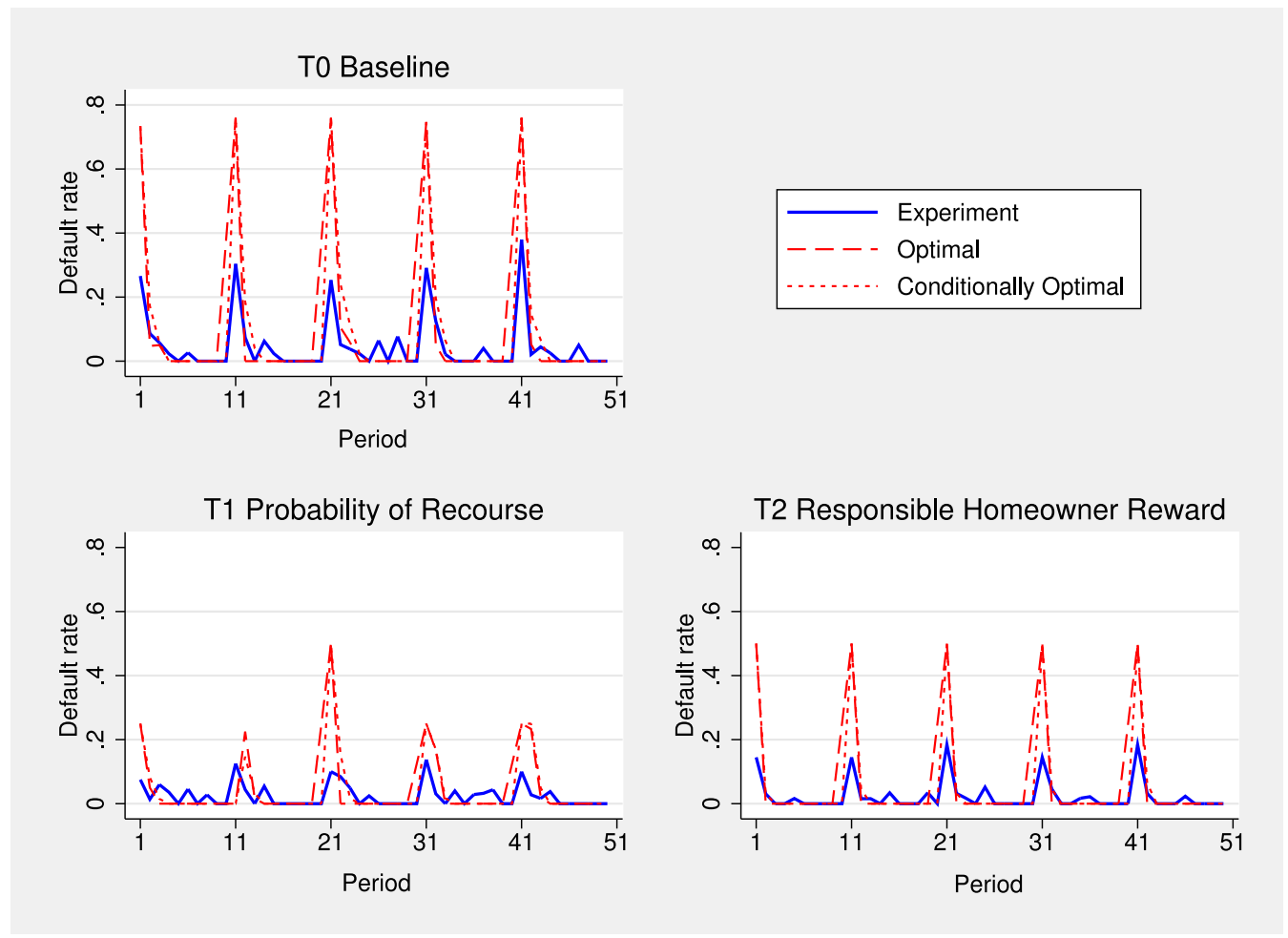

Fig. 3. Actual versus optimal default rates, by treatment. Note: The default rate is calculated as the percentage of homeowners who default. In the horizontal axis, periods 1-10 correspond to the first life, periods $11-20$ to the second life, and so on up to period 50 .

Table 6

Default rates in period 1, life 5: optimal vs. observed.

\begin{tabular}{|c|c|c|c|c|c|c|}
\hline \multirow[t]{2}{*}{ Initial Condition } & \multicolumn{2}{|c|}{ T0 Baseline } & \multicolumn{2}{|c|}{ T1 Recourse } & \multicolumn{2}{|c|}{ T2 RH Reward } \\
\hline & Theory & Experiment & Theory & Experiment & Theory & Experiment \\
\hline$\left(y^{L}, P^{L}\right)$ & $100 \%$ & $57 \%$ & $0 \%$ & $\begin{array}{l}15 \% \\
(\mathrm{z}=2.8, \mathrm{p}=\mathbf{0 . 0 0 6})\end{array}$ & $100 \%$ & $\begin{array}{l}21 \% \\
(\mathrm{z}=2.33, \mathrm{p}=\mathbf{0 . 0 2 0})\end{array}$ \\
\hline$\left(y^{H}, P^{L}\right)$ & $100 \%$ & $37 \%$ & $0 \%$ & $\begin{array}{l}15 \% \\
(z=1.56, p=0.118)\end{array}$ & $0 \%$ & $\begin{array}{l}16 \% \\
(z=1.47, p=0.14)\end{array}$ \\
\hline$\left(y^{L}, P^{H}\right)$ & $100 \%$ & $35 \%$ & $100 \%$ & $\begin{array}{l}5 \% \\
(\mathrm{z}=2.37, \mathrm{p}=\mathbf{0 . 0 1 8})\end{array}$ & $100 \%$ & $\begin{array}{l}5 \% \\
(\mathrm{z}=2.3, \mathrm{p}=\mathbf{0 . 0 2 2})\end{array}$ \\
\hline$\left(y^{H}, P^{H}\right)$ & $0 \%$ & $21 \%$ & $0 \%$ & $\begin{array}{l}5 \% \\
(\mathrm{z}=1.5, \mathrm{p}=0.134)\end{array}$ & $0 \%$ & $\begin{array}{l}32 \% \\
(z=-0.74, p=1.000)\end{array}$ \\
\hline All & $75 \%$ & $38 \%$ & $25 \%$ & $\begin{array}{l}10 \% \\
(\mathrm{z}=4.1, \mathrm{p}<\mathbf{0 . 0 0 1})\end{array}$ & $50 \%$ & $\begin{array}{l}18 \% \\
(\mathrm{z}=2.7, \mathrm{p}=\mathbf{0 . 0 0 8})\end{array}$ \\
\hline
\end{tabular}

Note: The default rate is calculated as the percentage of homeowners defaulting. For each of the two treatments $\mathrm{T} 1$ and $\mathrm{T} 2$, between parenthesis we report the $z$-value $(z)$ and the $p$-value (p) of a one-tail proportion test comparing the default rate in period 1 of life 5 between the baseline and that treatment. All $p$-values have been Bonferroni corrected to take into account the problem of false positives in multiple comparisons.

should happen in the first periods might have been demanding on our experimental subjects. Early default prevents the participants from experiencing the effects of alternative decisions (keeping the house, or selling it later on), while forcing them to rent until the end of the mortgage life. However, we do not find evidence of experimentation and learning in this decision: even if default rates are slightly increasing with the experience acquired over lives, these differences are not significant, so that default appears to be quite a stable decision.

Table 6 shows theoretical and observed default rates as a function of income and house price realizations in the first period of the last life, for each treatment. For those initial shock combinations leading to default with certainty in the baseline model, in the experiment we observe about 40-65\% less default than predicted, as can be seen in the first two columns of the table. On the other hand, a non-trivial fraction (21\%) of individuals receiving the highest income and the highest house price do not pay the debt installment in the first period even if that is not the utility maximizing choice. As in our model, and coherent with the "double trigger" hypothesis, individuals taking part in the baseline treatment default (much) more 
Table 7

Logit regressions of the default decision: theory vs. data.

\begin{tabular}{|c|c|c|c|c|c|c|}
\hline \multirow[t]{2}{*}{ PANEL A: T0 Baseline } & \multicolumn{2}{|c|}{$\begin{array}{l}(1) \\
\text { Optimal Default }\end{array}$} & \multicolumn{2}{|c|}{$\begin{array}{l}\text { (2) } \\
\text { Cond. Opt. Default }{ }^{\mathrm{a}}\end{array}$} & \multicolumn{2}{|c|}{$\begin{array}{l}\text { (3) } \\
\text { Observed Default }\end{array}$} \\
\hline & Coeff. & St. Err. & Coeff. & St. Err. & Coeff. & St. Err. \\
\hline Constant (LYLP) & $31.06^{* * *}$ & $(6.68)$ & $51.06^{* * *}$ & $(11.72)$ & -0.29 & $(0.50)$ \\
\hline HYLP & $-13.36^{* * *}$ & $(3.29)$ & $-28.04^{* * *}$ & $(7.04)$ & $-1.42^{* * *}$ & $(0.32)$ \\
\hline LYHP & $-7.19^{* *}$ & $(3.17)$ & $-13.04^{* * *}$ & $(3.54)$ & $-1.44^{* * *}$ & $(0.29)$ \\
\hline HYHP & $-23.44^{* * *}$ & $(4.07)$ & $-38.24^{* * *}$ & $(7.81)$ & $-2.02^{* * *}$ & $(0.33)$ \\
\hline Initial Assets & $-12.33^{* * *}$ & $(4.06)$ & $-9.85^{* * *}$ & $(2.77)$ & -0.09 & $(0.14)$ \\
\hline Period in life & $-6.53^{* * *}$ & $(1.34)$ & $-13.44^{* * *}$ & $(2.93)$ & $-0.53^{* * *}$ & $(0.13)$ \\
\hline Life & 0.00 & $(0.73)$ & 0.14 & $(0.58)$ & 0.15 & $(0.10)$ \\
\hline Number of Obs. & 885 & & 1828 & & 1828 & \\
\hline Chi Squared & 45.52 & & 45.60 & & 74.23 & \\
\hline$P$-value & $<0.001$ & & $<0.001$ & & $<0.001$ & \\
\hline \multirow[t]{2}{*}{ PANEL B: T1 Recourse } & \multicolumn{2}{|c|}{ Optimal Default ${ }^{\mathrm{a}}$} & \multicolumn{2}{|c|}{ Cond. Opt. Default ${ }^{\mathrm{a}}$} & \multicolumn{2}{|c|}{ Observed Default ${ }^{\mathrm{b}}$} \\
\hline & Coeff. & St. Err. & Coeff. & St. Err. & Coeff. & St. Err. \\
\hline Constant (LYLP) & $3.11^{* * *}$ & $(0.82)$ & -0.16 & $(0.54)$ & $-3.03^{* * *}$ & $(0.64)$ \\
\hline HYLP & $-4.66^{* * *}$ & $(1.44)$ & $-4.40^{* * *}$ & $(1.44)$ & $-0.79^{* *}$ & $(0.37)$ \\
\hline LYHP & $5.88^{* * *}$ & $(0.77)$ & $3.73^{* * *}$ & $(0.36)$ & -0.11 & $(0.42)$ \\
\hline HYHP & $-4.40^{* * *}$ & $(1.44)$ & $-4.44^{* * *}$ & $(1.44)$ & $-1.45^{* * *}$ & $(0.52)$ \\
\hline Initial Assets & $-7.72^{* * *}$ & $(1.12)$ & $-1.41^{* * *}$ & $(0.47)$ & 0.02 & $(0.11)$ \\
\hline Period in life & $-2.03^{* * *}$ & $(0.29)$ & $-1.21^{* * *}$ & $(0.18)$ & $-0.20^{* *}$ & $(0.09)$ \\
\hline Life & $0.32^{* *}$ & $(0.15)$ & $0.24^{* *}$ & $(0.11)$ & 0.06 & $(0.11)$ \\
\hline Number of Obs. & 1830 & & 2202 & & 2202 & \\
\hline Chi Squared & 85.98 & & 153.87 & & 26.77 & \\
\hline$P$-value & $<0.001$ & & $<0.001$ & & $<0.001$ & \\
\hline \multirow[t]{2}{*}{ PANEL C: T2 Responsible Homeowner Reward } & \multicolumn{2}{|c|}{ Optimal Default ${ }^{\mathrm{a}}$} & \multicolumn{2}{|c|}{ Cond. Opt. Default ${ }^{\mathrm{a}}$} & \multicolumn{2}{|c|}{ Observed Default ${ }^{\mathrm{b}}$} \\
\hline & Coeff. & $\overline{\text { St. Err. }}$ & Coeff. & $\overline{\text { St. Err. }}$ & Coeff. & $\overline{\text { St. Err. }}$ \\
\hline Constant (LYLP) & $12.84^{* * *}$ & (3.59) & $24.16^{* * *}$ & $(4.76)$ & $-3.29 * * *$ & $(0.90)$ \\
\hline HYLP & $-10.38^{* * *}$ & $(2.04)$ & $-15.36^{* * *}$ & $(2.57)$ & -0.51 & $(0.43)$ \\
\hline LYHP & 0.03 & $(1.91)$ & $-5.04^{* * *}$ & $(1.63)$ & -0.40 & $(0.46)$ \\
\hline HYHP & $-10.39^{* * *}$ & $(2.04)$ & $-15.36^{* * *}$ & $(2.57)$ & $-1.02^{*}$ & $(0.57)$ \\
\hline Initial Assets & $-4.96^{* * *}$ & $(1.77)$ & $-6.05^{* * *}$ & $(2.05)$ & -0.01 & $(0.06)$ \\
\hline Period in life & $-5.00 * * *$ & $(0.94)$ & $-11.40^{* * *}$ & $(2.21)$ & $-0.50 * * *$ & $(0.14)$ \\
\hline Life & -0.01 & $(0.81)$ & 0.15 & $(0.38)$ & 0.16 & $(0.14)$ \\
\hline Number of Obs. & 1609 & & 2409 & & 2409 & \\
\hline Chi Squared & 52.41 & & 54.38 & & 29.02 & \\
\hline$P$-value & $<0.001$ & & $<0.001$ & & $<0.001$ & \\
\hline
\end{tabular}

a Firth bias-corrected logit regression.

b Panel logit regression, Robust Standard Errors.

${ }^{* * *}=$ significant at $1 \% ;{ }^{* *}=$ significant at $5 \% ;{ }^{*}=$ significant at $10 \%$

Note: The dependent variable is a dummy equal to 1 for a homeowner defaulting, 0 for homeowners paying the mortgage or selling the house. Columns (1) and (2) display Firth bias-correction logit regressions of the unconditionally and conditionally optimal default decision respectively, using the data generated from the numerical solution of the model. Column (3) shows the results of a random effects panel logit regression of the observed default decision, with vector corrected errors clustered at the individual level. The regressors are the following:

HYLP: a dummy equal to 1 if high income and low house price shock, 0 otherwise.

LYHP: a dummy equal to 1 if low income and high house price shock, 0 otherwise.

HYHP: a dummy equal to 1 if high income and high house price shock, 0 otherwise.

Initial Assets: the value of initial assets. In column (1) this variable is the optimal initial assets given all the past history of income and house price shocks. In columns (2) and (3), it is the actual assets owned by a subject at the beginning of the period.

Period in Life: decision period, between 0 and 10 .

Life: between 1 and 5 .

when receiving the unemployment and the low house price shocks. The default rate of individuals characterized by $\left(y^{L}, P^{L}\right)$ is $57 \%$, significantly higher than the one of the $\left(y^{H}, P^{H}\right.$ ) (using a proportion test: $z$-value $=2.33$ and $p$-value $=0.02$ ).

Both experimental treatments successfully discourage strategic default with respect to the control one, in the theory and in the data. Globally, while in the Baseline treatment on average $40 \%$ of subjects default at some point in life, this rate is reduced to $20 \%$ and $22 \%$ in T1 and $\mathrm{T} 2$ respectively. The corresponding optimal default rates would be $77 \%$ in $\mathrm{T} 0,37 \%$ in $\mathrm{T} 1$ and $50 \%$ in $\mathrm{T} 2$. Thus, the observed reduction in $\mathrm{T} 1$ is proportionally similar to the theoretical one, while that in $\mathrm{T} 2$ is even bigger than predicted. As can be observed in the last row of Table 6, with respect to the baseline treatment, the introduction of a $50 \%$ probability of recourse leads to a $74 \%$ reduction of observed default rates in the first period, which is the one characterized by the deepest negative house equity. On the other hand, the introduction of the Responsible Homeowner Reward more than halves observed mortgage default in the first period. The decrease in observed default rates is statistically significant using proportion tests ( $z$ - and $p$-values reported in Table 6). These effects are in fact stronger than 
the ones predicted by the theory for the first period, that are equal to a two thirds and a one third reduction respectively. Notice that treatments are effective in decreasing default especially for individuals with low income, while in the theory they should be more effective under low house price shocks. For subjects starting the period with the $\left(y^{L}, P^{H}\right)$ combination, in fact, while both treatments should have no effect at all according to the theory, they do succeed in preventing default in the laboratory. The income shock thus seems to play an important role in the default decision.

As underlined above, all observed default in the experiment is strategic, given that by construction all our subjects have the ability to pay the mortgage installment and consume the minimum consumption level of 0.5 . An alternative definition of strategic default is the one adopted by Gerardi et al. (2018), according to which strategic defaulters are those households that could make their mortgage payment without reducing consumption. In our data, we can interpret the observed consumption choice in the period of default as the subject's "desired" consumption. We can also compute the residual resources of each defaulter in the alternative case of having paid the mortgage as the sum of her income shock and initial assets, net of the mortgage installment. ${ }^{27}$ In the spirit of Gerardi et al. (2018), we call "highly" strategic defaulters those individuals whose residual resources if paying the mortgage are higher than the "desired" consumption. That is, a defaulter $i$ observed in $t$ is "highly" strategic if:

$$
y_{i t}+a_{i t} R-m>\tilde{c}_{i t}
$$

where we denote with a tilde the subject's observed consumption. We find that about $25 \%$ of the defaulters in each treatment are "highly" strategic, that is, they could afford to consume the same amount if paying the mortgage. Only $0.3 \%$ of defaulters ( 1 observation) is such that residual resources are higher than the sum of their observed consumption and saving choices, a sign that these "highly" strategic defaulters choose the default option because they want to save more. In fact, the mean saving of "highly" strategic defaulters is about 4.5 tokens (in all treatments), against an average saving of 0.6 by the rest of defaulters. Coherently, "highly" strategic defaulters are also characterized by a significantly higher degree of risk aversion (Mann-Whitney $U$ test $z$-value $=-3.74, p$-value $<0.001$ ).

\subsection{The determinants of the strategic default decision}

How do the state variables, the existence of punishment or rewards, and other individual characteristics affect default behavior? Our first exercise is that of comparing the observed to the theoretical effect of the state variables on the default decision, in each treatment. Table 7 presents results from logit regressions in which the dependent variable is a dummy equal to 1 for a defaulting homeowner, 0 for someone paying the mortgage or selling the house. Columns 1 and 2 of each panel in the table display logit regression estimates of the unconditionally and conditionally optimal default decision, respectively, using data generated by the numerical solution of the three theoretical models (in panels A, B and C). Notice that the optimal default decisions are completely determined by each combination of initial state variables, which would generate a separation problem in standard logit regressions. That is why we estimate Firth bias-corrected logit regressions, that use a penalized maximum likelihood estimation method originally developed to reduce the bias of maximum likelihood estimates in generalized linear models, but proven to be an ideal solution to a separation issue for the logistic regression (Heinze and Schemper, 2002). The independent variables are dummies for the realized income and house price shock combinations, the assets owned before taking the decision (theoretical in regression 1, and observed in regression 2), period and life. In other terms, for each model, these regressions estimate the (natural) logarithm of the odds resulting from the default policy functions. Regression 3 in each panel shows the estimated coefficients of a random effects panel logit regression of the observed default decision on the same explanatory variables as regression 2 , with vector corrected errors clustered at the individual level.

In treatment T0 (panel A), coherent with the theory, subjects receiving the low unemployment income and the lowest house price (used as the baseline of the regression) are more likely to default than all other types of shock combinations. With a positive probability of recourse (panel B), a higher income diminishes the likelihood of default, in the experiment as well as in the theory. In the case of low income, instead, the lower negative equity induced by a high house price is predicted to increase default with respect to the baseline, given the lower amount to be repaid in case of punishment. This does not happen in the experiment, where the most important role seems to be played by the unemployment shock, as already noticed in the above subsection. In the Responsible Homeowner Reward treatment (panel C), experiment participants of different types do not differ in their default behavior, while according to the theory high income households should default less. Summing up, while receiving a certain combination of income and house price shocks does affect the likelihood of default in the baseline, only the high income shock significantly reduces observed default in treatment T1, and the two shocks are not important to discriminate experimental behavior in T2. Last, higher assets at the beginning of the period diminish the likelihood of default in all three theoretical models, but do not have any significant effect in the experiment. As observed above, default should and does happen in the first periods of life, and there is in fact no evidence of "learning" to default over lives. ${ }^{28}$

\footnotetext{
27 A limit in Gerardi et al. (2018) is that they do not have adequate wealth information to be able to calculate residual resources as defined above. They compute residual income instead: total income minus the mortgage payment. Under this definition, they find that $38 \%$ of defaulters are strategic.

28 In treatment T1, the significant effect of life on the optimal default decision is due to the unbalanced composition of types in lives 2 and 3 , as observed above.
} 
Next, we assess the significance of the differences observed between the treatments. In the panel logit regressions reported in Table 8, the dependent variable is the observed default decision by homeowners. In the first regression, controlling for the same state variables as in Table 7, the estimated coefficients on two treatment dummies are both negative and significant. In regression 2 we interact the state variables with the treatment dummies. Both treatments are estimated to significantly discourage the default of the low income types, especially in combination of a low house price, but have almost no effect for individuals with high income. Notice that in T1 default is less decreasing over life than in the other two treatments. In other terms, the existence of a positive probability of recourse has the effect of delaying the default decision to periods in which negative equity is lower. All these effects are robust to the introduction of control variables on subjects' socio-demographic characteristics, test results and answers to the questionnaire, in regression 3 . The only questionnaire items whose answers have a significant effect on the probability of default are the ones regarding behavior in the experiment, while the ones asking for moral or social norm considerations in general do not play any role. ${ }^{29}$ In particular, agreeing that participants in the experiment should have paid their debts decreases the likelihood of default, while believing that the default rate in the experiment is higher drives participants to default more. We conclude that an important predictor of default in the experiment is the perceived social norm in the laboratory, while moral and social norm concerns in general do not affect the observed default behavior. This might suggest that survey questions on normative behavior in hypothetical situations are not necessarily coherent with respondents' actions, at least in an experimental context. Gender, risk aversion or reasoning ability do not have any significant impact on the default decision, while subjects who have more experience in lab experiments are more likely to default, probably due to the fact that they are less concerned about their behavior in these contexts. ${ }^{30}$

Last, we also analyzed the role of future income and house price expectations, information on which we retrieved only in the last life due to the time constraint in a 50-period long experiment. One possible reason for continuing with the mortgage payments despite being deeply underwater is the expectation that house prices will increase in the future. This belief is found to have a significant positive effect on the likelihood of mortgage repayment only in T1. In this treatment, a lower expected negative house equity implies a lower expected punishment in the future, thus postponing the default decision. Expected income has no effect. ${ }^{31}$

\subsection{Consumption behavior}

Fig. 4 shows actual consumption choices versus unconditionally and conditionally optimal consumption, by treatment. Average optimal consumption is increasing over life given that households cannot borrow and the initial distribution of incomes is balanced, with an average income of 8 , while the stationary distribution is characterized by only a $14 \%$ of agents receiving low income and an average income of $9.43 .{ }^{32}$ Subjects' deviation from optimal behavior is lower for conditionally optimal consumption, given that in this case past "mistakes" are not taken into account. The almost coincidence of the actual and conditionally optimal consumption levels in the last period is due to the fact that it is very easy for individuals to understand that in the last period it is optimal to convert all their assets into points to maximize their gains. Compared to the unconditionally optimal behavior, subjects tend to under-consume at the beginning of their lives, and over-consume at the end. This is in sharp contrast with evidence from life-cycle consumption/saving experiments, in which overconsumption is observed at the beginning of life (Ballinger et al., 2003; Brown et al., 2009; Carbone and Hey, 2004 among others). Meissner (2016), however, finds that underconsumption is observed when subjects need to borrow in order to reach optimal consumption levels. Our results suggest that individuals that start life deeply indebted (even if only in the context of a lab experiment) are reluctant to consume, an indication perhaps of debt aversion.

Consumption does not vary much across treatments, even if in T2 we can clearly observe the effect of the Responsible Homeowner Reward received in period 5: participants do not smooth it over time, but rather increase the number of tokens they convert into points in that period.

To measure how "optimal" each experimental subject's consumption decision is, we can calculate the difference $d_{i t}=$ $\widetilde{c}_{i t}-c_{t}^{j_{i t}}\left(\widetilde{a}_{i t}, \widetilde{y}_{i t}, \widetilde{P}_{i t}\right)$, where the superscript $j_{i t}$ in the consumption policy function is equal to $o$ if subject $i$ is a homeowner in period $t, j_{i t}=r$ if she is a renter, and we denote with a tilde the observed variables in the experiment. That is, $d_{i t}$ is the "directional" deviation of actual consumption from the conditionally optimal one for individual $i$ in period $t$ (see for example Ballinger et al., 2003). These deviations allow us to measure the extent to which individuals under- or over-consume with respect to what is predicted by the theory, given their initial state variables. Alternatively, we can also consider the absolute deviation $D_{i t}=\left|d_{i t}\right|$, whose statistics give a better idea of how far observed consumption is from the conditionally optimal

\footnotetext{
${ }^{29}$ Strangely, the answers to the questionnaire are not very correlated among them. Only item a) "People should pay their debts" has a coefficient of correlation of $35 \%$ with item c) "I feel morally obliged to pay my debts", of $-26 \%$ with question d) "Sometimes it is justified not to pay one's debts", and of $17 \%$ with question e) "People should have paid their debts in this experiment" (all correlations significant, with a p-value lower than 0.001). Eliminating answer to item a) from the regression, however, preserves all the results.

${ }^{30}$ The correlations among our socio-demographic and individual characteristics variables are low. Lab experience has a 0.18 correlation coefficient with age, and removing the latter from regression 3 does not alter the results.

31 These results are available upon request.

32 Notice that the average income in the experiment can differ across lives and treatments and from the theoretical means since there are only $76-80$ subjects per treatment. As a consequence, despite drawing the shocks according to the theoretical Markov process, it is not possible to get the exact theoretical income distribution.
} 
Table 8

Determinants of the default decision and treatment effects.

\begin{tabular}{|c|c|c|c|c|c|c|}
\hline & \multicolumn{2}{|c|}{ (1) Observed default } & \multicolumn{2}{|c|}{ (2) Observed default } & \multicolumn{2}{|c|}{ (3) Observed default } \\
\hline & Coeff. & St. Err. & Coeff. & St. Err. & Coeff. & St. Err. \\
\hline Constant (LYLP) & $-0.89 * *$ & $(0.39)$ & -0.37 & $(0.51)$ & 0.78 & $(2.20)$ \\
\hline T1 Recourse & $-1.63^{* * *}$ & $(0.42)$ & $-2.76^{* * * *}$ & $(0.77)$ & $-2.64 * * *$ & $(0.81)$ \\
\hline T2 RH Reward & $-1.64 * * *$ & $(0.46)$ & $-2.40^{* * *}$ & $(0.88)$ & $-2.14^{* *}$ & $(0.87)$ \\
\hline HYLP & $-1.01^{* * *}$ & $(0.21)$ & $-1.46^{* * *}$ & $(0.33)$ & $-1.47^{* * *}$ & $(0.33)$ \\
\hline HYLP $\times \mathrm{T} 1$ & & & 0.66 & $(0.49)$ & 0.80 & $(0.50)$ \\
\hline HYLP $\times$ T2 & & & $0.97^{*}$ & $(0.52)$ & $0.96^{*}$ & $(0.52)$ \\
\hline LYHP & $-0.78^{* * *}$ & $(0.22)$ & $-1.50^{* * *}$ & $(0.30)$ & $-1.48^{* * *}$ & $(0.30)$ \\
\hline LYHP $\times$ T1 & & & $1.39 * * *$ & $(0.52)$ & $1.54^{* * *}$ & $(0.51)$ \\
\hline LYHP $\times$ T2 & & & $1.11^{* *}$ & $(0.52)$ & $1.09^{* *}$ & $(0.52)$ \\
\hline HYHP & $-1.61^{* * *}$ & $(0.26)$ & $-2.08^{* * *}$ & $(0.34)$ & $-2.09 * * *$ & $(0.34)$ \\
\hline HYHP $\times$ T1 & & & 0.62 & $(0.62)$ & 0.77 & $(0.64)$ \\
\hline HYHP $\times$ T2 & & & $1.1^{*}$ & $(0.63)$ & $1.11^{*}$ & $(0.64)$ \\
\hline Initial Assets & -0.04 & $(0.06)$ & -0.09 & $(0.14)$ & -0.09 & $(0.14)$ \\
\hline Initial Assets $\times \mathrm{T} 1$ & & & 0.12 & $(0.18)$ & 0.12 & $(0.18)$ \\
\hline Initial Assets $\times \mathrm{T} 2$ & & & 0.08 & $(0.15)$ & 0.09 & $(0.15)$ \\
\hline Period in life & $-0.40^{* * *}$ & $(0.07)$ & $-0.51^{* * *}$ & $(0.13)$ & $-0.51^{* * *}$ & $(0.13)$ \\
\hline Period in life $\times \mathrm{T} 1$ & & & $0.32^{* *}$ & $(0.15)$ & $0.32^{* *}$ & $(0.15)$ \\
\hline Period in life $\times \mathrm{T} 2$ & & & -0.00 & $(0.19)$ & -0.01 & $(0.19)$ \\
\hline Life & $0.12^{*}$ & $(0.07)$ & 0.16 & $(0.11)$ & 0.16 & $(0.11)$ \\
\hline Life $\times \mathrm{T} 1$ & & & -0.10 & $(0.15)$ & -0.12 & $(0.15)$ \\
\hline Life $\times \mathrm{T} 2$ & & & -0.02 & $(0.16)$ & -0.02 & $(0.17)$ \\
\hline Should pay & & & & & -0.33 & $(0.30)$ \\
\hline Do pay & & & & & 0.16 & $(0.19)$ \\
\hline Morally obliged & & & & & 0.10 & $(0.26)$ \\
\hline Justified not to pay & & & & & -0.09 & $(0.15)$ \\
\hline Should have paid & & & & & $-0.27^{* *}$ & $(0.13)$ \\
\hline$\%$ not paying? & & & & & $0.03^{* * *}$ & $(0.01)$ \\
\hline Risk Aversion & & & & & -0.11 & $(0.20)$ \\
\hline Reasoning Ability & & & & & 0.02 & $(0.03)$ \\
\hline Age & & & & & -0.01 & $(0.02)$ \\
\hline Lab Experience & & & & & $0.33^{* *}$ & $(0.14)$ \\
\hline Financial Situation & & & & & -0.40 & $(0.34)$ \\
\hline Female & & & & & -0.25 & $(0.37)$ \\
\hline Number of Obs. & 6439 & & 6439 & & 6427 & \\
\hline Chi Squared & 129.55 & & 158.62 & & 188.16 & \\
\hline$P$-value & $<0.001$ & & $<0.001$ & & $<0.001$ & \\
\hline
\end{tabular}

${ }^{* * *}=$ significant at $1 \% ;{ }^{* *}=$ significant at $5 \% ;{ }^{*}=$ significant at $10 \%$.

Note: The three columns display the estimated coefficients of random effects panel logit regressions (robust standard errors in parenthesis). The dependent variable is a dummy equal to 1 if the homeowner subject decided to default, 0 otherwise.

The regressors are the following:

T1: a dummy equal to 1 if the observation belongs to the Recourse treatment.

T2: a dummy equal to 1 if the observation belongs to the Responsible Homeowner Reward treatment.

HYLP: a dummy equal to 1 if high income and low house price shock, 0 otherwise.

LYHP: a dummy equal to 1 if low income and high house price shock, 0 otherwise.

HYHP: a dummy equal to 1 if high income and high house price shock, 0 otherwise.

Initial Assets: the value of initial assets.

Period in Life: decision period, between 0 and 10.

Life: between 1 and 5 .

Should pay: answer to Questionnaire point a), between 1 and 5 .

Do pay: answer to Questionnaire point b), between 1 and 5 .

Morally obliged: answer to Questionnaire point c), between 1 and 5 .

Justified not to pay: answer to Questionnaire point d), between 1 and 5 .

Should have paid: answer to Questionnaire point e), between 1 and 5 .

\% not paying: answer to Questionnaire point f), between 0 and 100 .

Risk aversion: scale resulting from the risk aversion test (the higher, the higher the risk aversion).

Reasoning ability: number of correct answers in the DAT-Abstract Reasoning test, between 0 and 40 .

Age: age in years.

Lab experience: Discrete variable for experience in the lab: $0=$ never participated, $1=1$ to 3 times, $2=4$ to 6 times, $3=7$ to 9 times, $4=$ more than 9 times.

Financial situation: Discrete variable indicating the financial situation of the subject's family: $1=$ we endure very hard times, $2=$ can just make ends meet,

$3=$ live moderately well, $4=$ we are well off.

Female: equal to 1 if the subject is a female. 

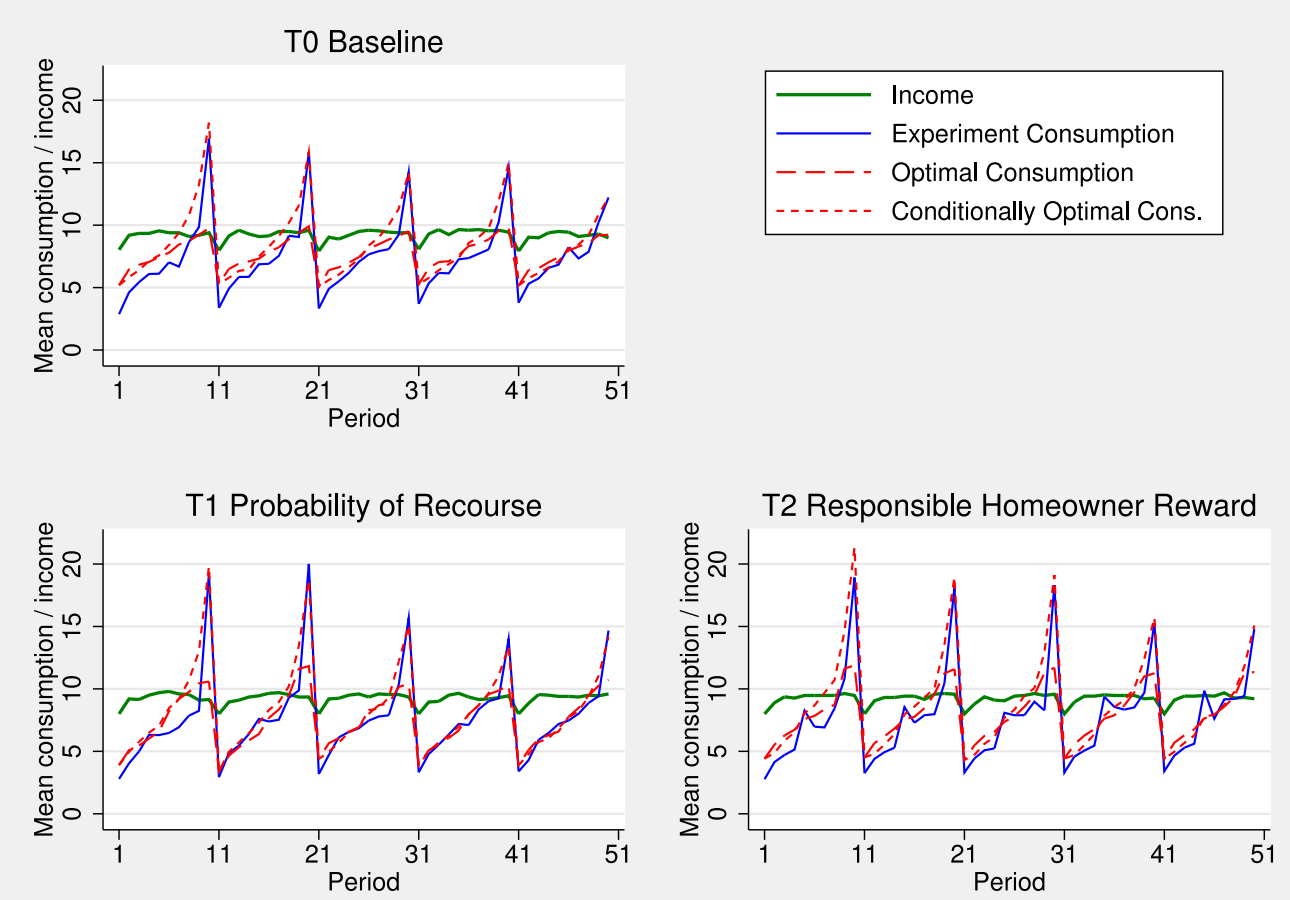

Fig. 4. Actual versus optimal mean consumption, by treatment. Note: In the horizontal axis, periods 1-10 correspond to the first life, periods $11-20$ to the second life, and so on up to period 50 .
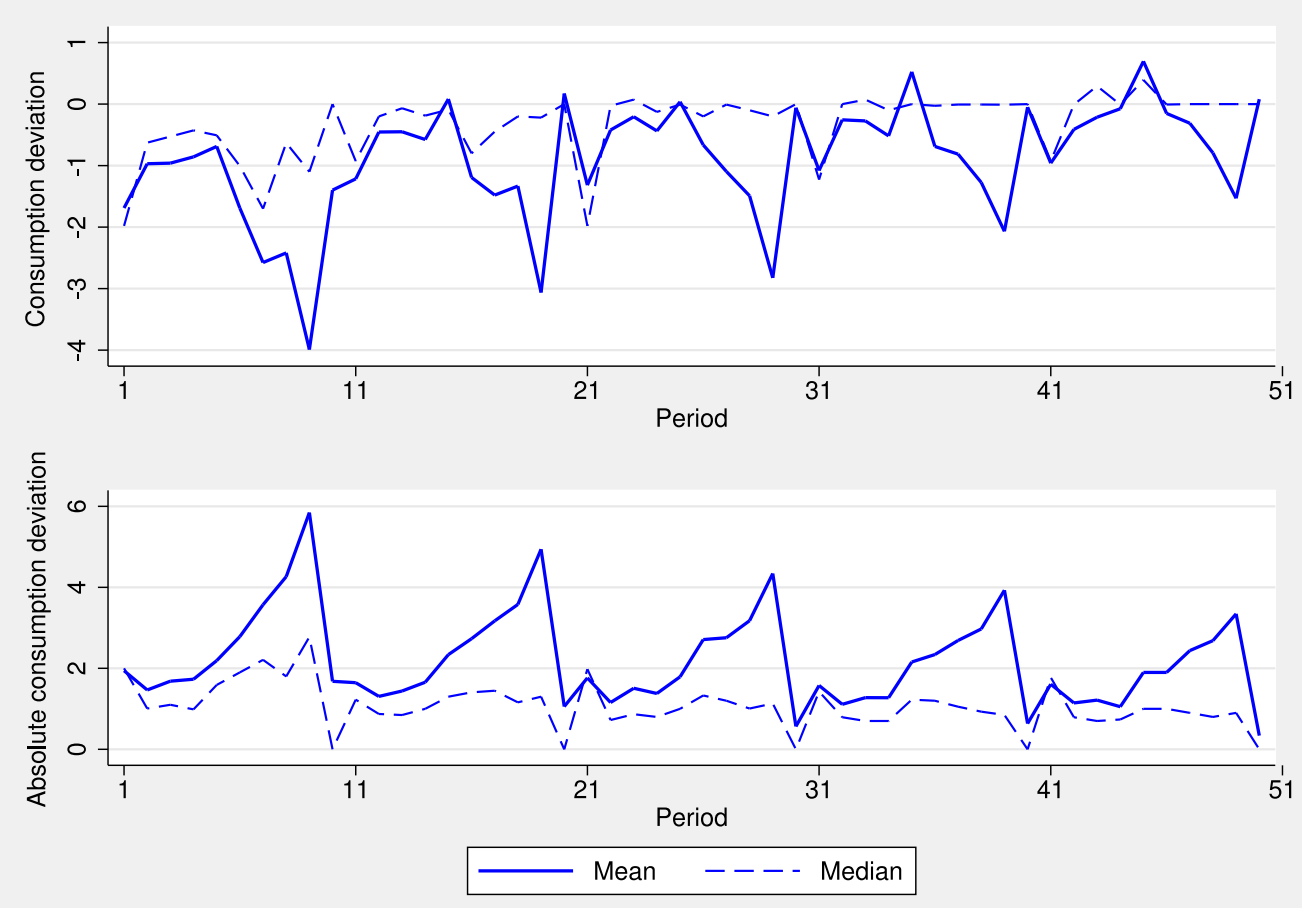

Fig. 5. Directional and absolute consumption deviations from conditionally optimal. Note: Directional deviation is the difference between observed and conditionally optimal consumption. 
Table 9

Determinants of consumption.

\begin{tabular}{|c|c|c|c|c|c|c|c|c|}
\hline \multirow[t]{2}{*}{ Variables } & \multicolumn{2}{|c|}{$\begin{array}{l}\text { (1) } \\
\text { Optimal Consumption }\end{array}$} & \multicolumn{2}{|c|}{$\begin{array}{l}\text { (2) } \\
\text { Cond. Optimal Consumption }\end{array}$} & \multicolumn{2}{|c|}{$\begin{array}{l}\text { (3) } \\
\text { Obs. Consumption }\end{array}$} & \multicolumn{2}{|c|}{$\begin{array}{l}\text { (4) } \\
\text { Obs. Consumption }\end{array}$} \\
\hline & Coeff. & St. Err. & Coeff. & St. Err. & Coeff. & St. Err. & Coeff. & St. Err. \\
\hline Constant (LYLP) & $2.83^{* * *}$ & $(-0.08)$ & $-2.27^{* * *}$ & $(0.41)$ & $-1.47^{* * *}$ & $(0.31)$ & $-1.66^{* * *}$ & $(0.43)$ \\
\hline T1 Recourse & $-0.34^{* * *}$ & $(0.02)$ & $-0.41^{* * *}$ & $(0.12)$ & 0.12 & $(0.15)$ & 0.002 & $(0.13)$ \\
\hline T2 RH Reward & $0.12^{* * *}$ & $(0.02)$ & $-0.32^{* * *}$ & $(0.13)$ & 0.16 & $(0.11)$ & 0.11 & 0.11 \\
\hline HYLP & $2.10^{* * *}$ & $(0.05)$ & $1.48^{* * *}$ & $(0.14)$ & $2.50 * * *$ & $(0.15)$ & $2.50^{* * *}$ & $(0.15)$ \\
\hline LYHP & $0.24^{* * *}$ & $(0.07)$ & $0.83^{* * *}$ & $(0.15)$ & $0.47^{* * *}$ & $(0.17)$ & $0.48^{* * *}$ & $(0.17)$ \\
\hline HYHP & $2.40^{* * *}$ & $(0.05)$ & $2.27^{* * *}$ & $(0.12)$ & $3.02 * * *$ & $(0.14)$ & $3.02^{* * *}$ & $(0.15)$ \\
\hline Initial Assets & $0.37^{* * *}$ & $(0.01)$ & $0.42^{* * *}$ & $(0.02)$ & $0.21^{* * *}$ & $(0.02)$ & $0.22^{* * *}$ & $(0.02)$ \\
\hline Homeowner & $-0.2^{* * *}$ & $(0.03)$ & $3.36 * * *$ & $(0.22)$ & $0.90^{* * *}$ & $(0.17)$ & $1.01^{* * *}$ & $(0.16)$ \\
\hline Period in life & $0.45^{* * *}$ & $(0.01)$ & $1.20^{* * *}$ & $(0.06)$ & $0.97 * * *$ & $(0.04)$ & $0.97 * * *$ & $(0.04)$ \\
\hline Life & 0.00 & $(0.01)$ & -0.04 & $(0.03)$ & $0.12^{* * *}$ & $(0.02)$ & $0.13^{* * *}$ & $(0.02)$ \\
\hline Risk Aversion & & & & & & & $-0.20^{* * *}$ & $(0.07)$ \\
\hline Reasoning Ability & & & & & & & $0.02^{* * *}$ & $(0.01)$ \\
\hline Age & & & & & & & 0.001 & $(0.01)$ \\
\hline Lab Experience & & & & & & & 0.10 & $(0.06)$ \\
\hline Financial Situation & & & & & & & $-0.20^{*}$ & $(0.10)$ \\
\hline \multirow[t]{5}{*}{ Female } & & & & & & & $0.33^{* * *}$ & $(0.12)$ \\
\hline & Obs. & 11750 & Obs. & 11750 & Obs. & 11750 & Obs. & 11700 \\
\hline & R sq. & 0.66 & R sq. & 0.50 & R sq. & 0.30 & R sq. & 0.30 \\
\hline & Adj. R sq. & 0.66 & Adj. R sq. & 0.50 & Adj. R sq. & 0.30 & Adj. R sq. & 0.30 \\
\hline & F stat & 4242.52 & F stat & 529.37 & F stat & 407.66 & F stat & 268.16 \\
\hline
\end{tabular}

${ }^{* * *}=$ significant at $1 \% ;{ }^{* *}=$ significant at $5 \% ;{ }^{*}=$ significant at $10 \%$.

Note: The table displays the estimated coefficients of OLS regressions, with robust standard errors clustered at the individual level between parentheses. In columns (1) and (2), the dependent variable is a continuous variable reflecting the unconditionally and conditionally optimal consumption level of the simulated agent, respectively. In columns (3) and (4), the dependent variable is the observed consumption choice in the experiment.

The regressors are the following:

HYLP: a dummy equal to 1 if high income and low house price shock, 0 otherwise.

LYHP: a dummy equal to 1 if low income and high house price shock, 0 otherwise.

HYHP: a dummy equal to 1 if high income and high house price shock, 0 otherwise.

Initial Assets: the value of initial assets. In column (1), this variable is the optimal initial assets given all the past history of income and house price shocks. In columns (2), (3) and (4), it is the actual assets owned by a subject at the beginning of the period.

Homeowner: a dummy equal to 1 if the individual is a homeowner at the beginning of the period. In column (1), this variable is the optimal homeownership given all the past history of income and house price shocks.

Period in Life: decision period, between 0 and 10.

Life: between 1 and 5 .

Risk aversion: scale resulting from the risk aversion test (the higher, the higher the risk aversion).

Reasoning ability: number of correct answers in the DAT-Abstract Reasoning test, between 0 and 40 .

Age: age in years.

Lab experience: Discrete variable for experience in the lab: $0=$ never participated, $1=1$ to 3 times, $2=4$ to 6 times, $3=7$ to 9 times, $4=$ more than 9 times.

Financial situation: Discrete variable indicating the financial situation of the subject's family: $1=$ we endure very hard times, $2=$ can just make ends meet, $3=$ live moderately well, $4=$ we are well off.

Female: equal to 1 if the subject is a female.

one. Fig. 5 depicts the mean and median of the directional and absolute deviations from conditionally optimal behavior over the five lives, pooling all treatments data. We observe that subjects consume less than the optimal given their initial states, except in period 5, due to the effect of the Responsible Homeowner Reward in treatment T2. In contrast to the default decision, we observe learning taking place in consumption choices (in accordance with Brown et al., 2009).

Last, we analyze the effect of the state variables, treatments and other individual characteristics on the consumption decisions. Results are presented in Table 9, that displays the estimated coefficients of OLS regressions with robust standard errors clustered at the individual level. ${ }^{33}$ The dependent variables are unconditionally and conditionally optimal consumption in regressions 1 and 2 respectively, and observed consumption in regressions 3 and 4 . The first three regressions include dummies for treatments T1 and T2, and the main state variables in the household's problem: dummies for income and house price shock combinations, initial assets, a dummy equal to 1 if the individual is a homeowner, and period. We also control for life, in order to capture possible learning effects. The fourth regression adds to these variables the results of the risk aversion and reasoning ability tests together with other individual characteristics.

The estimated effects of the income and house price shock combinations and of initial assets on observed consumption are of the same sign as and similar magnitude to the theoretical ones. In particular, the higher the income, the higher the number of points converted. The effect of the house price on consumption is also positive (a positive wealth effect), but quantitatively lower. A higher value of initial assets also significantly increases consumption, with a weaker effect in the data than in the models. Moreover, theoretical and observed consumption are increasing over the life cycle, as already

\footnotetext{
${ }^{33}$ We pool all our data because we do not observe significant differences in consumption behavior among treatments.
} 
shown in Fig. 4. Being a homeowner leads to higher conditionally optimal consumption, with a similar but weaker effect in the experiment. Given that in general individuals tend to under-consume in the experiment, the regression results confirm the existence of some learning in the consumption decision, since the coefficient on the variable "life" is positive and significant. Treatments have a significant small effect on optimal consumption, but do not change consumption behavior in the laboratory.

The above results are robust to the introduction of subjects' socio-demographic and other characteristics as explanatory variables. Higher risk aversion leads to lower consumption levels in the experiment, coherently with the theoretical result that risk aversion increases precautionary savings (Bommier and Le Grand, 2019). A better result in the reasoning ability test increases consumption, that is, makes it closer to the optimal one, even if this effect is quite small in magnitude. Females and participants who are experiencing a hard time at home also consume more in the experiment. Laboratory experience and age do not significantly affect the consumption choice.

\section{Discussion and conclusion}

Subjects in our experiment are confronted with a complex, dynamic, problem in which they face risky income, have to make consumption/saving decisions under borrowing constraints, and must choose whether to pay back an inherited debt on an asset whose value has decreased and is uncertain. Our set-up intends to capture the main features of the problem faced by a household with a mortgage in a situation of economic crisis. We numerically simulate optimal individual behavior that is solution to this problem, and compare it to the actual choices of human experiment participants. Using an experimental methodology allows us to control fundamental variables that would be very difficult to perfectly observe in the field, such us available wealth, negative equity, consumption, etc. In our theory, depending on the initial income and house price shock combination, the choice that would maximize subjects' welfare would often be to strategically default on the mortgage, that is, to "walk away" from the house despite their ability to pay. Our results show that experiment participants do not do a bad job in solving the dynamic optimization problem: they default in the right periods and quite fast learn what they should consume within five life cycles, in line with Brown et al. (2009). Homeownership and consumption behavior in the laboratory tracks quite well optimal behavior in a conditional sense: given the state variables characterizing the beginning of the period, subjects do not deviate much from the utility maximizing choices. Moreover, some of the key theoretical state variables (the income and house price shocks, the time period and, in the case of the consumption choice, homeownership and initial assets) are estimated to significantly affect individuals' decisions in a way coherent with the theory. In particular, we find experimental evidence supporting the "double trigger" hypothesis suggested by many in the literature (Foote et al., 2008; Schelkle, 2018, and others): the combination of low income and low house price (high negative equity) increases the likelihood of default.

In our baseline experiment, we create an environment in which there does not exist social stigma, there are no serious consequences of default (apart from a small cost paid immediately), house equity is known with certainty at the beginning of the period, and subjects hardly feel any emotional attachment to their housing asset. Despite all that, however, experiment participants default much less than optimal: the observed default rate is about half the one predicted by the baseline theory. We analyze how default behavior is affected by a number of socio-demographic and other individual characteristics. We find that social norm concerns retrieved from a questionnaire significantly affect the probability of default only when explicitly referring to the context of the experiment. In particular, subjects who state that participants should have paid their debts in the experiment are less likely to default, suggesting that what people perceive as the social norm does matter for their decision. Moreover, individuals who report a higher expected default rate in the experiment default more, a hint that contagion effects may be important, as suggested by Guiso et al. (2013), and documented in Bradley et al. (2015) and Goodstein et al. (2017). An experiment in which participants are provided with information about actual peer behavior would be helpful to further explore these effects. ${ }^{34}$ Individual statements on the moral obligation and on the social norms of serving one's debts in general do not play any role in explaining default behavior in the laboratory, an indication, perhaps, that answers to survey questions are not necessarily coherent with individuals' actions. ${ }^{35}$ Risk aversion, cognitive ability, gender, age and the subject's current financial situation are found to have no significant impact on the default decision. The fact that cognitive ability is not relevant might be an indication that a poor understanding of the strategic situation in our game is not behind the results: if problem understanding was an issue, those with high cognitive ability would be observed to default more ${ }^{36}$ Laboratory experience increases the likelihood of default, probably due to the fact that individuals that often participate in experiments feel less concerns about their behavior in the lab. An alternative explanation could be that experienced subjects become better at utility maximizing. Of the individuals who do default, only about one quarter are

\footnotetext{
34 A recent study of the link between social norms and default behavior is the one by Brown et al. (2016). In their experiment, they manipulate the information available to social norm "enforcers" about the strategic nature of defaults, in a static setting. They find that in an economic downturn there is less norm enforcement due to the increased difficulty in distinguishing between strategic and "innocent" defaulters.

35 In a way, it is not surprising that general moral concerns about default do not affect repayment behavior in a laboratory. They could still be important factors affecting real default behavior. The surprising result is that subjects do not default much despite the fact that they are only playing a game in a laboratory.

36 The results of the DAT-AR test show high variance in cognitive ability in our sample. The number of correct answers ranges from 0 to 40 , with a mean
} of 23.4 and a standard deviation of 7.5. 
found to be "highly" strategic in the sense of Gerardi et al. (2018), that is, decide not to pay despite the fact that they could afford the same consumption level if serving the mortgage. These subjects are characterized by higher risk aversion and save much more than the rest of defaulters.

An important advantage of our methodology is that it allows to analyze the impact of alternative policies on real subjects' behavior. Two experimental treatments that introduce economic incentives to deter default are highly effective, halving the percentage of participants who default at some point in life. Again, in line with the "double trigger" hypothesis, the treatments are especially effective for individuals receiving a bad shock to income. In the first treatment (T1) there exists a $50 \%$ probability that the defaulter is punished with the repayment of the mortgage debt not covered by the collateral. This reduces observed strategic default by approximately $75 \%$ in the first period (the one in which most default should and does take place). The punishment in this treatment is harsher for a deeper negative equity, and should be more effective under low house prices. In the experiment, the existence of a probability of recourse significantly reduces the default rates of the individuals receiving the unemployment shock in periods characterized by low prices. This treatment has also the effect of somewhat delaying the default decision to periods in which negative equity is lower. One possible reading of the results from this treatment is that an important deterrent of default is the fear of its consequences. This is coherent with what Ghent and Kudlyak (2011) find in their investigation of the U.S. states, that "the effect of recourse is not reflected in the frequency of deficiency judgments but, instead, in the way the threat of recourse alters borrower behavior" (Ghent and Kudlyak, 2011; p. 3140). ${ }^{37}$

Our second experimental treatment (T2) consists in a "Responsible Homeowner" Reward in the spirit of Edmans' (2010), to be paid to the homeowner once house equity turns positive with certainty, in the middle of the mortgage life. This treatment is even more effective than the theory predicts. The observed default rate is decreased by $50 \%$, while theoretically only a $33 \%$ reduction was expected. Again, it is the unemployed individuals in low price periods who respond more to the incentive introduced by the RH reward. Differently from T1, treatment T2 delays the selling decision: individuals hold on to their house at least up to the reward period. The results from this treatment underline the importance of incentives to impact default behavior, particularly in a situation in which default is the individual's choice. The implementation of a reward program of the kind we test has the advantage of being relatively cheap for the lenders compared with the high costs of loan modifications. Moreover, the program allows homeowners to self select into it, decreasing the tax payers' costs with respect to interventions that target borrowers' income, and allaying the problem of asymmetric information that characterize these policies. However, one subsisting problem with a reward scheme is that the provider can end up paying rewards to homeowners that would have paid their mortgage anyway (see Edmans', 2010). From this consideration, there arises the need of targeting the scheme only to some types of borrowers. Our study suggests that the program would be particularly effective for low income individuals in low house price periods. Future experimental research could be used to explore whether other observable characteristics increase the response rate to such a program, and to determine the optimal size of the reward.

Last, our study also contributes to the experimental literature on intertemporal consumption/saving decisions. In contrast to the results of most of these works, we find that individuals consume less than optimal in this experiment, especially in the first periods of life: they are "cautious" when indebted, coherently with debt aversion as found in Meissner (2016). Consumption decisions are not affected by treatments, even if, in treatment T2, the reward paid to the responsible homeowners in the fifth period causes an increase in consumption in that period. While socio-demographic and other individual characteristics do not have an impact on the default choice, some of them do affect the consumption decision. More risk averse individuals, for instance, are found to consume less, coherently with precautionary saving in the presence of uncertainty and borrowing constraints (Bommier and Le Grand, 2019). Moreover, the consumption of subjects with a higher cognitive ability is closer to optimal and female subjects also consume more.

One limitation in our study is that we focus on the individual default choice in isolation. Given our results that social norms are important, future research could analyze how this choice is linked to information on others' behavior in a dynamic setting under different policy regimes.

\section{Appendix A. Household's problem in recursive formulation and computational details}

The household's problem can be written in recursive formulation.

Given the vector of state variables $x_{t}=\left(a_{t}, y_{t}, P_{t}\right)$, the homeowner's value function is the following:

$$
V_{t}\left(x_{t}\right)=\max _{I_{t}^{o s d}}\left\{V_{t}^{o}\left(x_{t}\right), V_{t}^{s}\left(x_{t}\right), V_{t}^{d}\left(x_{t}\right)\right\}
$$

where $V_{t}^{o}\left(x_{t}\right), V_{t}^{s}\left(x_{t}\right), V_{t}^{d}\left(x_{t}\right)$ are the value functions for owning, selling and defaulting respectively, and $I_{t}^{o s d}$ is an indicator function for the discrete choices of owning (paying the mortgage), selling, and defaulting.

\footnotetext{
37 Ghent and Kudlyak (2011) find, coherently with our theory, that it is especially high negative equity loans that are less likely to default in recourse states. They do not have data on income or other types of individual shocks, so they can not test the hypothesis that there is a link between the impact of recourse and borrowers' income. Our findings suggest that this link is worth exploring with real data.
} 
The value function for paying the mortgage is

$$
\begin{aligned}
& V_{t}^{o}\left(x_{t}\right)=\max _{a_{t+1}, c_{t}}\left\{u\left(c_{t}, \theta_{1} \bar{h}\right)+\beta E V_{t+1}\left(x_{t+1}\right)\right\} \\
& \text { s.t. } \quad a_{t+1}=y_{t}+a_{t} R-c_{t}-m, \quad c_{t} \geq \underline{c}, \quad a_{t+1} \geq 0
\end{aligned}
$$

Expectations are taken with respect to the employment status and the house price, conditional on the current realization of these shocks.

The value for selling the house and pre-paying the mortgage is

$$
\begin{aligned}
& V_{t}^{s}\left(x_{t}\right)=\max _{a_{t+1}, c_{t}}\left\{u\left(c_{t}, \theta_{0} \bar{h}\right)+\beta E V_{t+1}^{r}\left(x_{t+1}\right)\right\} \\
& \text { s.t. } \quad a_{t+1}=y_{t}+a_{t} R-c_{t}+\bar{h} P_{t}(1-\phi)-M_{t}-\bar{h} P_{t}^{r}, \quad c_{t} \geq \underline{c}, \quad a_{t+1} \geq 0
\end{aligned}
$$

where we use the same notation as in the text, and $V^{r}$ is the renter's value function:

$$
\begin{aligned}
& V_{t}^{r}\left(x_{t}\right)=\max _{a_{t+1}, c_{t}}\left\{u\left(c_{t}, \theta_{0} \bar{h}\right)+\beta E V_{t+1}^{r}\left(x_{t+1}\right)\right\} \\
& \text { s.t. } \quad a_{t+1}=y_{t}+a_{t} R-c_{t}-\bar{h} P_{t}^{r}, \quad c_{t} \geq \underline{c}, \quad a_{t+1} \geq 0, P_{t}^{r}=\omega P_{t}
\end{aligned}
$$

The value for defaulting is instead:

$$
\begin{aligned}
& V_{t}^{d}\left(x_{t}\right)=\max _{a_{t+1}, c_{t}}\left\{u\left(c_{t}, \theta_{0} \bar{h}\right)+\beta\left[(1-\pi) E V_{t+1}^{r}\left(x_{t+1}\right)+\pi E V_{t+1}^{d r}\left(x_{t+1}, d_{t}\right)\right]\right\} \\
& \text { s.t. } \quad a_{t+1}=y_{t}+a_{t} R-c_{t}-\Psi-\bar{h} P_{t}^{r}, \quad c_{t} \geq \underline{c}, \quad a_{t+1} \geq 0, \quad P_{t}^{r}=\omega P_{t}
\end{aligned}
$$

We denote with $V^{d r}$ the value function of a renter who has defaulted before and is being punished, i.e. who must pay back (over time) the difference between the home value and the mortgage principal at the time of default:

$$
\begin{aligned}
& V_{t}^{d r}\left(x_{t}, d_{s}\right)=\max _{a_{t+1}, c_{t}}\left\{u\left(c_{t}, \theta_{0} \bar{h}\right)+\beta E V_{t+1}^{d r}\left(x_{t+1}, d_{s}\right)\right\} \\
& \text { s.t. } \quad a_{t+1}=y_{t}+a_{t} R-c_{t}-\bar{h} P_{t}^{r}-d_{s}, \quad c_{t} \geq \underline{c}, \quad a_{t+1} \geq 0, P_{t}^{r}=\omega P_{t}
\end{aligned}
$$

where the payment $d_{s}$ depends on the house price $P_{s}$ and the age $s$ at default in the following way:

$$
d_{s}=d\left(P_{s}, s\right)=\frac{r^{m}}{1-\left(1+r^{m}\right)^{-(T-s)}} \max \left\{M_{s}-\bar{h} P_{s}, 0\right\}
$$

Computational details

We specify a grid of 2001 points for assets, whose value goes from 0 to $20 .^{38}$

Starting from period $T$ backward, we compute each value function and the corresponding optimal policies for each combination of state variables, solving for the homeowner's and renter's problems separately. In computation, we set a minimum consumption (subsistence) level $\underline{c}$ of 0.5 .

We can then draw a series of the employment and house price shocks according to the corresponding stochastic processes, and use the policy functions to simulate the optimal decisions of each agent at any age.

\section{Appendix B. Questionnaire on debt repayment obligations}

Assess the following statements according to a scale from 1 (strongly disagree) to 5 (strongly agree):

a) People should pay back their debts.

b) People do pay back their debts.

c) I feel morally obliged to pay back all my debts.

d) In certain situations, it is fair not to pay back your debts.

e) People should have paid their debts in this experiment.

And answer to the following question:

f) What percentage of participants do you think have not paid back their debts in this experiment?

\section{Supplementary material}

Supplementary material associated with this article can be found, in the online version, at doi:10.1016/j.jedc.2019.103733.

\footnotetext{
${ }^{38}$ We check that the assets' maximum value is never chosen (i.e., that it is never binding).
} 


\section{References}

Artavanis, N., Spyridopoulos, I., 2018. Behavioral attributes of strategic default: evidence from the foreclosure moratorium in greece. Working Paper, SSRN. Ballinger, T.P., Palumbo, M.G., Wilcox, N.T., 2003. Precautionary saving and social learning across generations: an experiment. Econ. J. 113 (490), $920-947$.

T., Bao, Hommes, C., 2015. When speculators meet constructors: positive versus negative feedback in experimental housing markets. Working Paper $15-10$. CeNDEF University of Amsterdam.

Barreda-Tarrazona, I., Jaramillo-Gutiérrez, A., Navarro-Martínez, D., Sabater-Grande, G., 2011. Risk attitude elicitation using a multi-lottery choice task: real vs. hypothetical incentives. Span. J. Financ. Account. 40 (152), 609-624.

Bennett, G.K., Seashore, H.G., Wesman, A.G., 1974. DAT: Differential Aptitude Test. The Psychological Corporation.

Bhutta, N., Dokko, J., Shan, H., 2017. Consumer ruthlessness and mortgage default during the 2007 to 2009 housing bust. J. Financ. 72 (6), $2433-2466$.

Bommier, A., Le Grand, F., 2019. Risk aversion and precautionary savings in dynamic settings. Manag. Sci. 65 (3), $955-1453$.

Bradley, M.G., Cutts, A.C., Liu, W., 2015. Strategic mortgage default: the effect of neighborhood factors. Real Estate Econ. 43 (2), 271-299.

Brown, A.L., Chua, Z.E., Camerer, C.F., 2009. Learning and visceral temptation in dynamic saving experiments. Q. J. Econ. 124 (1), $197-231$.

Brown, M., Schmitz, J., Zehnder, C., 2016. Social norms and strategic default. Working Papers on Finance 1608. University of St. Gallen School of Finance.

Campbell, J.Y., Cocco, J.F., 2015. A model of mortgage default. J. Financ. 70 (4), 1495-1554.

Carbone, E., Hey, J.D., 2004. The effect of unemployment on consumption: an experimental analysis. Econ. J. 114 (497), 660-683.

Chatterjee, S., Eyigungor, B., 2015. A quantitative analysis of the U.S. housing and mortgage markets and the foreclosure crisis. Rev. Econ. Dyn. 18 (2), $165-184$.

Corbae, D., Quintin, E., 2015. Leverage and the foreclosure crisis. J. Polit. Econ. 123 (1), 1-65.

Cordero, A., Corral, S., 2006. DAT- 5 tests de aptitudes diferenciales. TEA Ediciones.

Davis, M.A., Lehnert, A., Martin, R.F., 2008. The rent-price ratio for the aggregate stock of owner-ocupied housing. Rev. Income Wealth 54 (2), 279-284.

Davis, M.A., Ortalo-Magné, F., 2011. Household expenditures, wages, rents. Rev. Econ. Dyn. 14 (2), $248-261$.

Deng, Y., Quigley, J.M., Order, R.V., 2000. Mortgage terminations, heterogeneity and the exercise of mortgage options. Econometrica 68 (2), 275-308.

Edmans, A., 2010. The responsible homeowner reward: an incentive-based solution to strategic mortgage default. SSRN eLibrary Working Paper Series.

Experian, O.W., 2011. Strategic default in mortgages: Q2 2011 update. Market Intelligence Reports.

Fischbacher, U., 2007. Z-Tree: zurich toolbox for ready-made economic experiments. Exp. Econ. 10 (2), 171-178.

Foote, C.L., Gerardi, K., Willen, P.S., 2008. Negative equity and foreclosure: theory and evidence. J. Urban Econ. 64 (2), $234-245$.

Gerardi, K., Herkenhoff, K., Ohanian, L.E., Willen, P.S., 2018. Can'T pay or won't pay? Unemployment, negative equity and strategic default. Rev. Financ. Stud. 31 (3), 1098-1131.

Ghent, A.C., Kudlyak, M., 2011. Recourse and residential mortgage default: evidence from U.S. states. Rev. Financ. Stud. 24 (9), $3139-3186$.

Goodstein, R., Hanouna, P., Ramirez, C.D., Stahel, C.W., 2017. Contagion effects in strategic mortgage default. J. Financ. Intermed. 30, 50-60.

Greiner, B., 2015. Subject pool recruitment procedures: organizing experiments with ORSEE. J. Econ. Sci. Assoc. 1 (1), 114-125.

Guiso, L., Sapienza, P., Zingales, L., 2013. The determinants of attitudes towards strategic default on mortgages. J. Financ. LXVIII (4), 1473-1515.

Harrison, G.W., Lau, M.I., Rutström, E.E., 2009. Risk attitudes, randomization to treatment, and self-selection into experiments. J. Econ. Behav. Org. 70 (3), 498-507.

Heinze, G., Schemper, M., 2002. A solution to the problem of separation in logistic regression. Stat. Med. 21, $2409-2419$.

Hey, J.D., Dardanoni, V., 1988. Optimal consumption under uncertainty: an experimental investigation. Econ. J. 98 (390), $105-116$.

Holt, C.A., Laury, S.K., 2002. Risk aversion and incentive effects. Am. Econ. Rev. 92 (5), 1644-1655.

Huber, S.J., Rott, C., Giusti, G., 2018. Preference for housing services and house price bubble occurrence: evidence from a macro-experiment. Working Paper 18-06. CeNDEF University of Amsterdam.

Iacoviello, M., Pavan, M., 2013. Housing and debt over the life cycle and over the business cycle. J. Monet. Econ. 60 (2), $221-238$.

Ikromov, N., Yavas, A., 2012. Asset characteristics and boom and bust periods: an experimental study. Real Estate Econ. 40 (3), $603-636$.

Jeske, K., Krueger, D., Mitman, K., 2013. Housing, mortgage bailout guarantees and the macro economy. J. Monet. Econ. 60 (8), $917-935$.

Kaplan, G., Mitman, K., Violante, G.L., 2019. The housing boom and bust: model meets evidence. Unpublished Manuscript.

Kau, J.B., Keenan, D.C., Kim, T., 1994. Default probabilities for mortgages. J. Urban Econ. 35 (3), 278-296.

Lambertini, L., Nuguer, V., Uysal, P., 2017. Mortgage default in an estimated model of the U.S. housing market. J. Econ. Dyn. Control 76, 171-201.

Lazear, E.P., 2000. Performance pay and productivity. Am. Econ. Rev. 90 (5), 1346-1361.

Magill, M., Quinzii, M., 2015. Prices and investment with collateral and default. J. Econ. Dyn. Control 51, 111-132.

Meissner, T., 2016. Intertemporal consumption and debt aversion: an experimental study. Exp. Econ. 19 (2), $281-298$.

National Association of Realtors, 2005. Structure, conduct, and performance of the real estate brokerage industry. Technical Report.

Rabanal, J.P., 2014. Strategic Default with Social Interactions: A Laboratory Experiment. In: Collins, S.M., Isaac, R.M., Norton, D.A. (Eds.), Research in Experimental Economics: Experiments in Financial Economics,. Emerald Group Publishing Limited, Vol. 16, pp. 31-52.

Sabater-Grande, G., Georgantzís, N., 2002. Accounting for risk aversion in repeated prisoners' dilemma games: an experimental test. J. Econ. Behav. Org. 48 (1), 37-50.

Schelkle, T., 2018. Mortgage default during the U.S. mortgage crisis. J. Money, Credit Bank. 50, 1101-1137.

Trautmann, S.T., Vlahu, R., 2013. Strategic loan defaults and coordination: an experimental analysis. J. Bank. Financ. 37 (3), $747-760$.

White, B.T., 2010. Underwater and not walking away: shame, fear and the social management of the housing crisis. Wake Forest Law Rev 45, 971-1023. 